SLACPUB-9038

February 2, 2001

\title{
OPTICAL PROPERTIES OF THE DIRC FUSED SILICA CHERENKOV RADIATOR
}

\author{
J. Cohen-Tanugi, M. Convery, B. Ratcliff, X. Sarazin, J. Schwiening, and J. Va'vra* \\ Stanford Linear Accelerator Center, Stanford University, \\ Stanford, CA 94309, USA
}

\begin{abstract}
The DIRC detector is successfully operating as the hadronic particle identification system for the BaBar experiment at SLAC. The production of its Cherenkov radiator required much effort in practice, both in manufacture and conception, which in turn required a large number of $R \& D$ measurements. One of the major outcomes of this $R \& D$ work was an understanding of methods to select radiation hard and optically uniform fused silica material. Others included measurement of the wavelength dependency of the internal reflection coefficient, and its sensitivity to the surface pollution, selection of the radiator support, selection of good optical glue, etc. This note summarizes the optical R\&D test results.
\end{abstract}

\section{INTRODUCTION}

The Detector of Internally reflected Cherenkov light (DIRC) [1] is a new type of Cherenkov ring imaging detectors, which has been operating successfully at the BaBar experiment at SLAC for over one year. The device uses synthetic fused silica bars (colloquially called synthetic quartz), which serve both as the Cherenkov radiator and as light guides transmitting the photons to an array of $\sim 11,000$ photomultiplier tubes (PMT). A fraction of the Cherenkov photons produced by tracks passing through the bars are trapped by total internal reflection and propagate down the bar with very little loss. A mirror at the far end reflects those photons that were originally traveling away from the detection end of the bar. At the end of the bar, photons pass through a fused silica wedge, which reflects those photons that would otherwise miss PMTs. Then photons pass through a window, which separates the box holding the bars from water. Water is the optical coupling medium between the bars and the PMT detector. The distance between the bar box window and the PMT detector is about $1.2 \mathrm{~m}$. Figure 1 shows the photon path as it leaves a five-meter long fused silica bar.

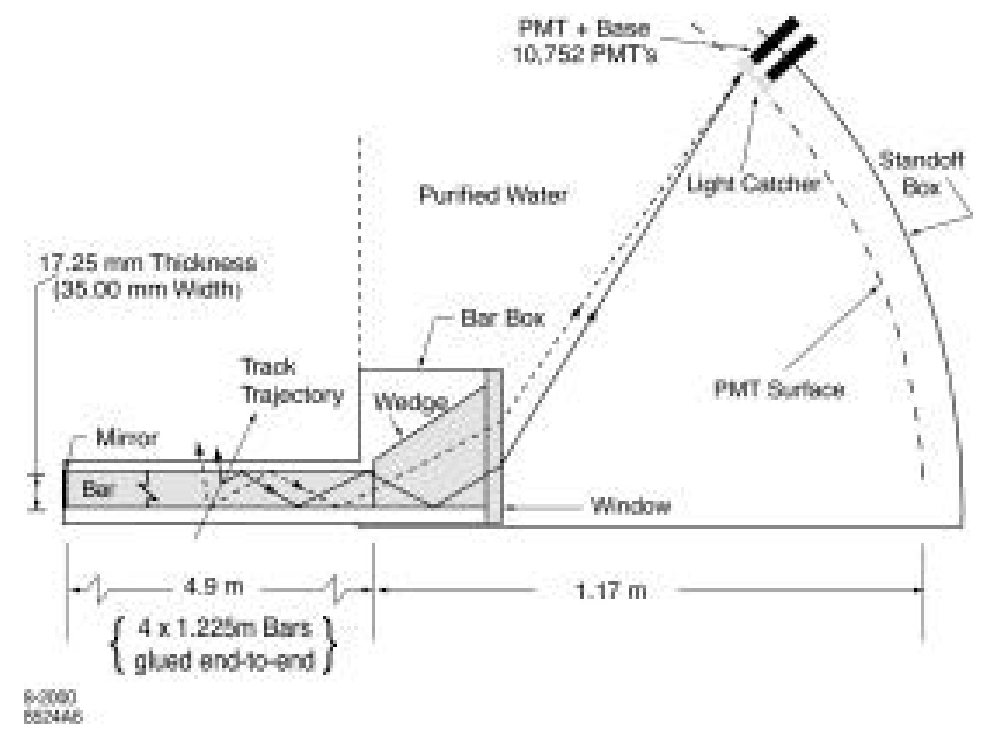

Figure 1. Imaging of Cherenkov photons with DIRC fused silica bar. A wedge at the end of each bar allows the proper placement of the image within the photon detector, which is made with 11000 PMTs.

\footnotetext{
* Work supported by the Department of Energy under contract DE-AC03-76SF00515
} 
Figure 2 shows a single bar box with 12 bars. Within the bar box, each bar measures $\sim 5 \mathrm{~m}$ in length and is made of four short segments glued together with EPOTEK 301-2 optical epoxy. ${ }^{1}$ Each short segment has the following design specifications: length $1225.0 \mathrm{~mm}$, width $35.0 \mathrm{~mm}$, and thickness $17.2 \mathrm{~mm}$. To preserve the image resolution and timing properties, the original specification was that any bar face-to-side angle to be within $\pm 0.25 \mathrm{mrad}$ of $90^{\circ}$ (see chapter 7 for a final compromise). The bars must have sharp edges without too many chips to limit photon losses (specifications required for less than $6 \mathrm{~mm}^{2}$ of damaged surface per bar). To check that the mechanical specifications are within our tolerances, we have built our own digital microscope system and developed our own image reconstruction software. Since the trapped Cherenkov photons must typically bounce several hundred times before they exit the bar, the internal reflection coefficient must be close to one. A reflectivity coefficient of less than 0.999 is unacceptable. Losses as small as $10^{-4}$ per bounce must be measured. Since such small losses are difficult to measure in a single bounce, we have developed a new method to measure the reflection coefficient by combining $~ 50$ bounces in a single measurement. The high value of surface reflectivity has to be maintained for expected ten-year lifetime of the experiment. Therefore, we studied a possible influence of fused silica surface pollution on the reflectivity coefficient. Another important factor is the bar transmission and its uniformity. Similarly, a problem of fused silica support within a bar box was a good subject for the R\&D tests. In addition, it was important to select radiation hard fused silica and optical glues. This is because the BaBar detector operates at a high luminosity machine (PEP II presently operates at a luminosity of $\sim 3 \times 10^{33} \mathrm{~cm}^{-2} \mathrm{sec}^{-1}$ and it is planned to go beyond $10^{34}$ in one to two years).

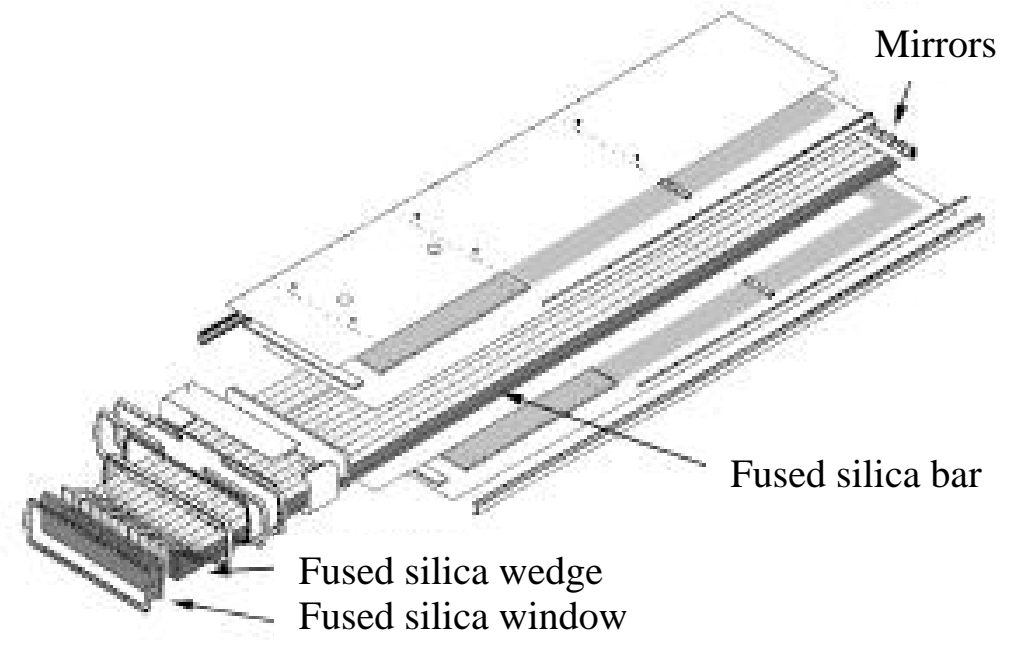

Figure 2. DIRC fused silica Cherenkov radiator as implemented in the BaBar experiment at SLAC. Twelve 5-m long fused silica bars are located in each bar box. There are 12 such bar boxes in the DIRC detector.

\section{BASIC PROPERTIES OF FUSED SILICA}

\subsection{Refraction Index}

To account for various effects in the DIRC, it is necessary to know the refraction index of water, fused silica, and EPOTEK 301-2 optical glue used for gluing the bars. Figure 3 shows the refraction index for fused silica [2] and water [3]. Figure 4 shows the calculated reflection coefficients at incidence angle of $0^{\circ}$ for the boundaries of fused silica/water and fused silica/EPOTEK 301-2 [4]. Due to a good match of the fused silica and glue refraction indices, the reflection coefficient is small (less than 0.15\%) and almost independent of wavelength above $300 \mathrm{~nm}$.

${ }^{1}$ Made by Epoxy Technology Inc., 14 Fortune Drive, Billerica, MA 01821, USA. 


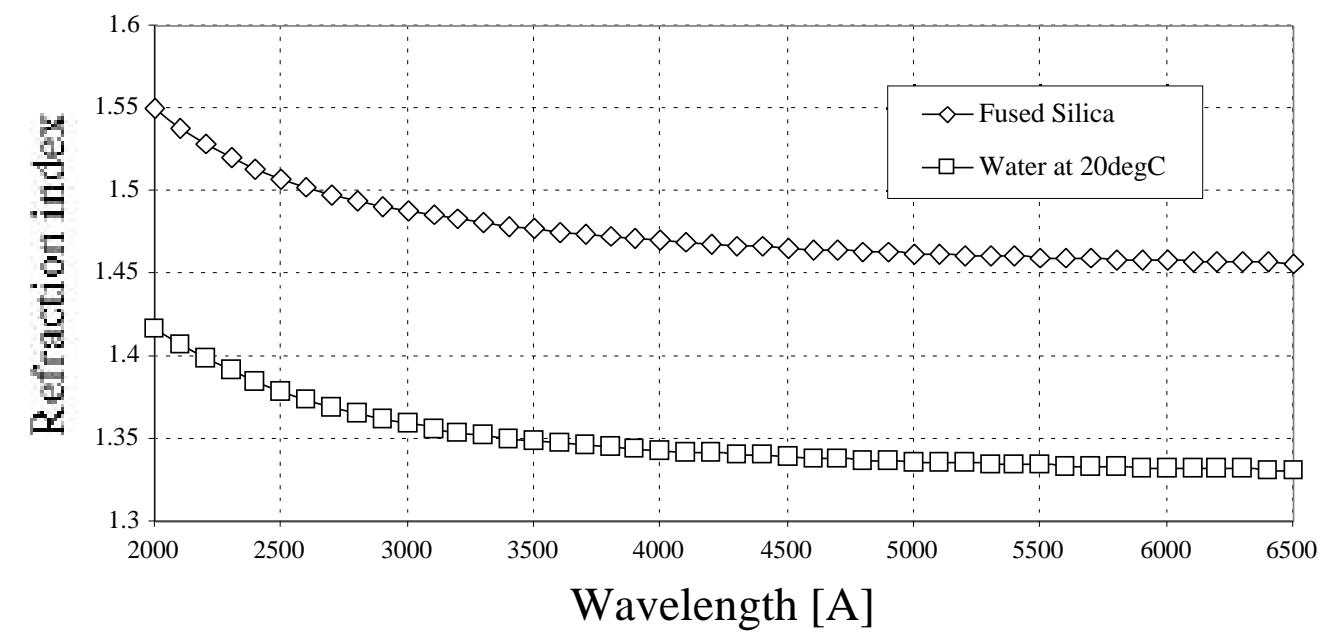

Figure 3. Wavelength dependence of the refraction indices for fused silica and water. The DIRC acceptance starts at $3000 \AA$.

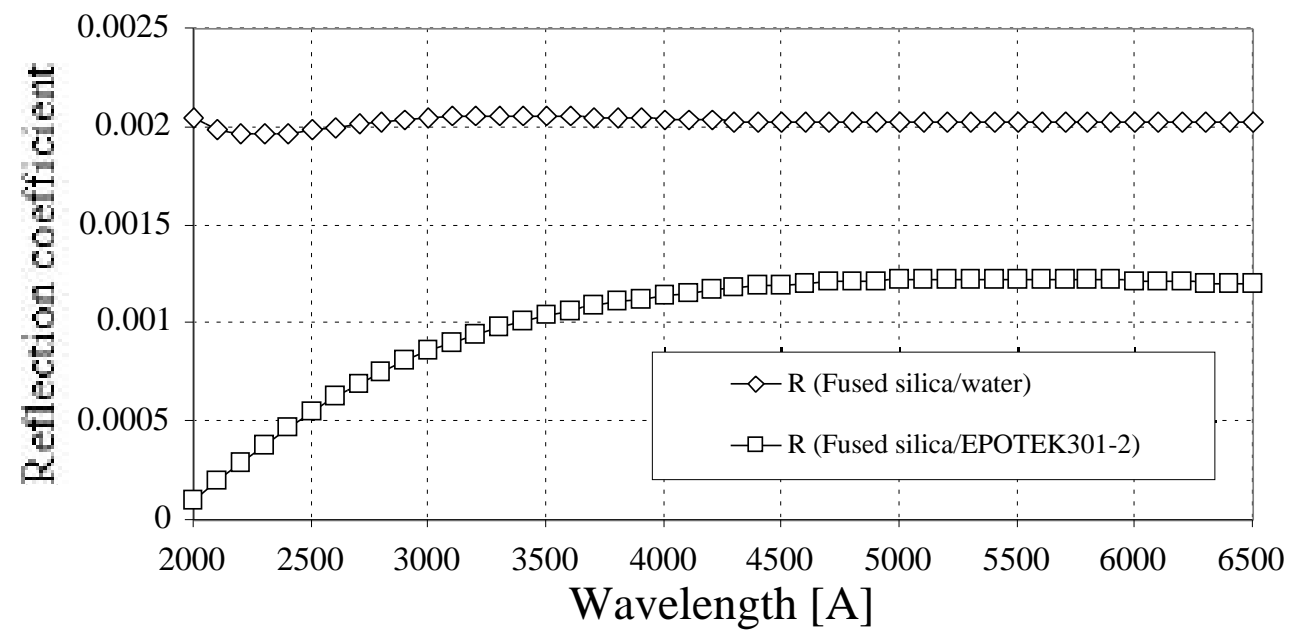

Figure 4. Wavelength dependence of the reflection coefficients for single fused silica-water, and fused silica-EPOTEK 301-2 interfaces at incidence angle of $0^{\circ}$. Notice that the fused silica-water reflection coefficient is almost independent of wavelength [5].

\subsection{Optical Bandwidth of DIRC}

Figure 5 shows a typical optical bandwidth of the DIRC detector for a particle at $90^{\circ}$ polar angle in BaBar [5], taking into account the fact that half of the Cherenkov photons bounce forward, i.e., towards the mirror side, and half bounce backward, i.e., towards the wedges. The bandwidth is somewhat sensitive to the track dip angle. One can see that the bandwidth is cut at $\sim 300 \mathrm{~nm}$, mainly due to the EPOTEK 301-2 glue transmission properties. This is actually advantageous for the DIRC because it reduces the chromatic error contributions to the overall Cherenkov angle and timing resolution. In addition, it makes the DIRC sensitive mainly in the visible wavelength region adding many practical advantages from a construction point of view. 


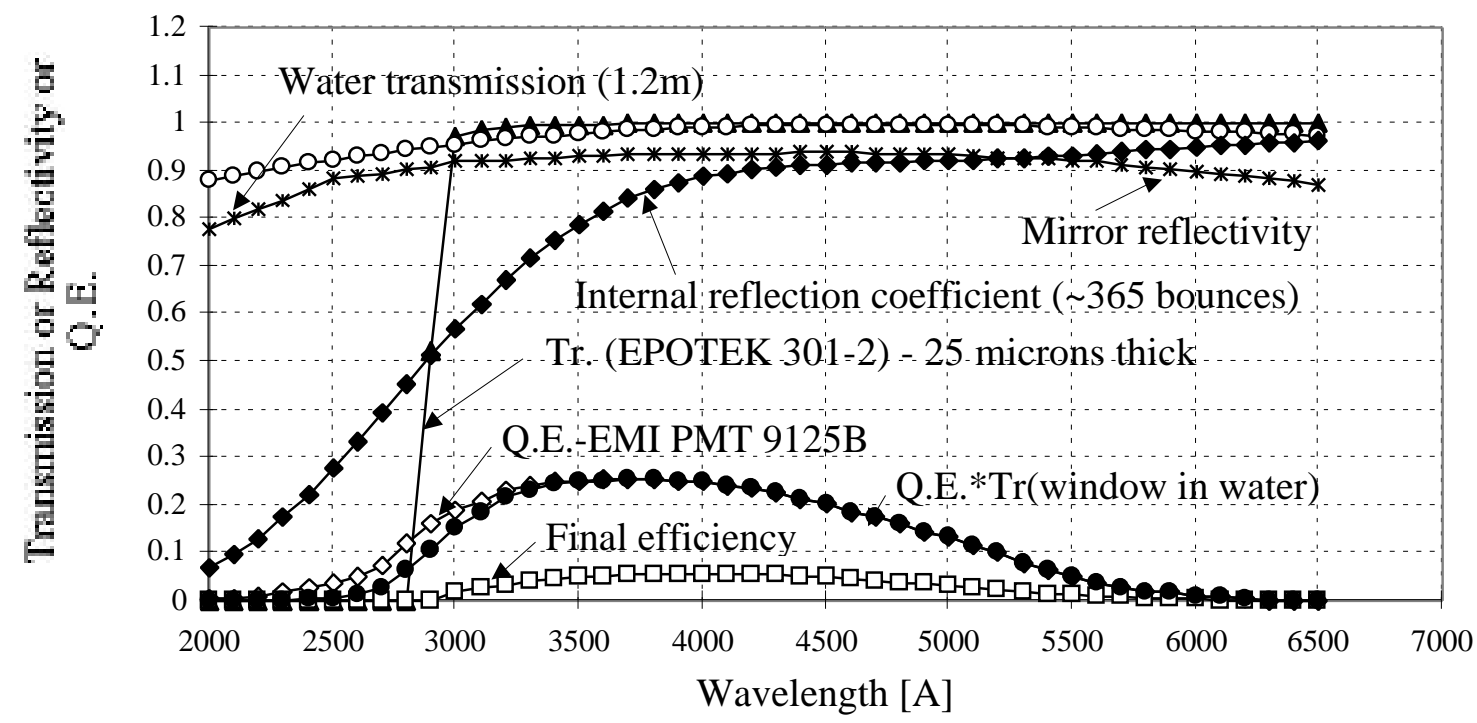

Figure 5. Contributions to the photoelectron detection efficiency for a track perpendicular to the fused silica bar located in the middle of the BaBar sensitive area, the quantum efficiency of the EMI9125B PMT is taken from manufacturer's

data, a transmission of one glue joint ( $25 \mu \mathrm{m}$ thick) made with EPOTEK 301-2 optical epoxy, water transmission over a $1.2 \mathrm{~m}$ long path, mirror reflectivity (affecting forward bouncing photons only), the internal reflection coefficient assuming $~ 365$ bounces (averaging over forward and backward photons). The DIRC final efficiency takes into account many other correction factors as well [5].

\subsection{Optical Homogeneity of Fused Silica Material}

One of the least expected features of the synthetic fused silica material produced in long ingots, such as used for DIRC, was that it possesses an observable periodic optical non-homogeneity in its volume [6]. This effect was initially discovered while shining a laser beam at non-zero angles relative to the bar axis and observing that some light was scattered into a diffraction-like pattern, called "lobes" (see Fig.6). This effect was observed in both types of fused silica considered for use in the DIRC - Heraeus Suprasil ${ }^{2}$ and QPC Spectrosil ${ }^{3}$.

This "lobe effect" was taken very seriously because it could cause photon losses, or image distortion of the Cherenkov light. A few additional features of the lobe effect were immediately observed:

a) The lobes were produced over a range of incident angles typically less than 45 degrees (or greater than $135^{\circ}$ ) relative to the bar axis.

b) For a given bar that produced lobes for incident angles less than 90 degrees relative to the bar axis, no lobes would be observed for angles greater than 90 degrees, and vice-versa.

c) Some bars produced no lobes at all.

The lobe pattern was suggestive of diffraction off of a periodic structure in the fused silica [9]. In fact, such a pattern could be directly observed using ordinary white light either in a microscope or with the collimated light of a slide projector. Figure 7 shows the pattern observed with an optical digital microscope configured as shown in Fig. 8. The same "directionality" was observed as for lobe production - i.e. the pattern was observed for $\theta>0$, but not for $\theta<0$. Also, the pattern persisted after removing $\sim 2 \mathrm{~mm}$ of material from each surface of the bar, thereby establishing that the pattern is in the volume of the fused silica material.

2 Synthetic fused silica material Suprasil Standard was made by Heraeus Amersil Co., 3473 Satelite Blvd., Duluth, GA 30136-5821.

3 Synthetic fused silica Spectrosil 2000 "high OH". Spectrosil is a trademark of TSL Group PCL, Wallsend, Tyne on Wear, NE28 6DG, England; Sold in the USA by Quartz Products Co. (QPC), 160 W. Lee Street, Louisville, Kentucky 40201. 
Although the lobe effect was initially observed in Heraeus fused silica, it is also present, although at lower intensity, in QPC fused silica material. Figure 9 shows the output of a photodiode as it is scanned across the lobe patterns of the two types of fused silica measuring the relative intensity. Evidently, the intensity of the lobes from QPC fused silica material $\left(\sim 3 \times 10^{-4}\right)$ is much smaller than from Heraeus $\left(\sim 3 \times 10^{-2}\right)$.

Figure 10 shows a model of the structure of the optical inhomogeneity, where it is assumed that there are curved "layers" of varying index of refraction within the fused silica ingots from which the bars are produced. If a laser beam is traveling tangent to these layers, than it would, in effect, see a "diffraction grating" formed by the alternating layers of high and low refraction index, thereby producing lobes. If however, the beam is traveling perpendicular to the layers, no lobes would be produced. This explains the "directionality" described above. Furthermore, we would expect that the opening angle of the lobes would be given by $\alpha=\lambda / \lambda$ ', where $\lambda$ is the wavelength of light and $\lambda^{\prime}$ is the spacing of the layers. Also, the phase change produced by the inhomogeneity would be $\Delta \varphi=4 \pi$ a $\left(\mathrm{R} \lambda^{\prime}\right)^{1 / 2} / \lambda$, where a is the amplitude of the inhomogeneity and $\mathrm{R}$ is the radius of curvature of the layers, which we assume are circular. The power in the lobes is proportional to the square of the phase change. So $\mathrm{f} \sim 1 / \lambda^{2}$. Measuring the lobes with two different light wavelengths can test the model. Figure 11 shows the results of the scans with $\mathrm{HeCd}$ blue line $(442 \mathrm{~nm})$ and the HeNe red line $(633 \mathrm{~nm})$. Table 1 shows the ratio of opening angles and lobe powers predicted by the model and those observed. The good agreement between the model and the measurements gives us confidence that the model is correct. Converting the measured power in the lobes to inhomogeneity amplitude (a), we find $\mathrm{a}=6 \times 10^{-6}$ for Heraeus and $1 \times 10^{-6}$ for QPC. More detailed measurements can also measure the shape of the layers in the fused silica.

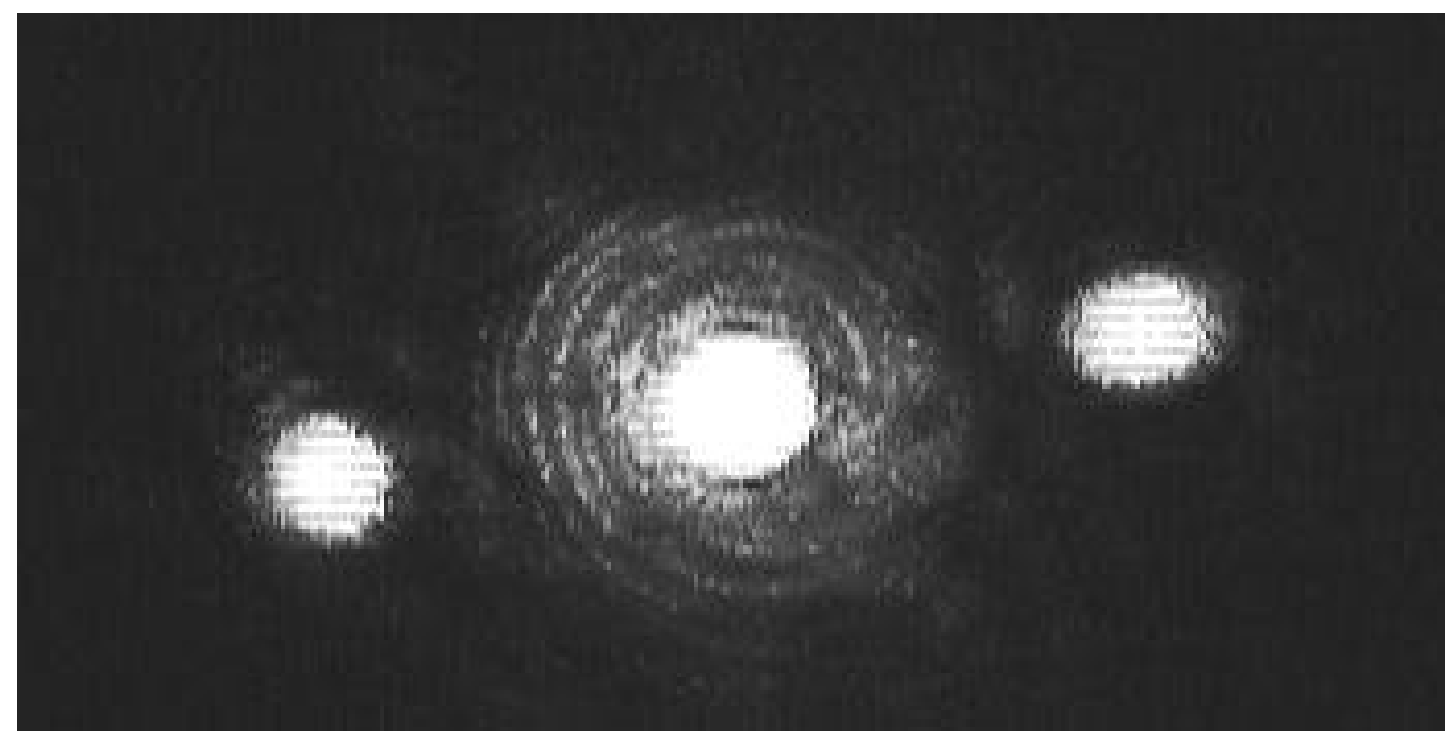

Figure 6. A lobe pattern created with a Ne-He laser in the synthetic fused silica Suprasil Standard [6].

Table 1 - Ratio of opening angles and power in the lobes.

\begin{tabular}{|c|c|c|}
\hline Variable & Predicted & Measured \\
\hline$\alpha$ (Blue) $/ \alpha$ (red) & 0.70 & $0.69 \pm 0.03$ \\
\hline $\mathrm{f}$ (blue ) / f (red) & 2.05 & $2.58 \pm 0.40$ \\
\hline
\end{tabular}

Because of its bright lobes, Heraeus material was rejected for use in the DIRC. QPC fused silica was deemed acceptable because of its lower lobe power, which was about 100 times weaker than Heraeus. Also, the lobes in QPC fused silica were usually produced at angles close to perpendicular to the bar axis, which are not relevant for the DIRC. It is interesting to note that no such lobes have been observed in any of our samples of natural silica, nor in the synthetic fused silica windows used for the CRID TPC detectors and liquid radiators [7]. In all of these 
cases, the $\mathrm{SiO} 2$ material is randomly deposited on top of previous layers. What makes the DIRC's synthetic material so special is that it is produced in a long ingot form, where the $\mathrm{SiO}_{2}$ material is deposited layer-by-layer while the ingot is rotating. The details of this process are proprietary, and so not directly accessible to us, but it seems very plausible that inhomogeneity amplitudes of a few times $10^{-6}$ could easily be produced by it. We should also point out that in most applications of synthetic fused silica, such as windows or optical fibers, the light is expected to travel only at angles close to parallel with the "bar axis". The DIRC may be one of the few applications where light must propagate at large angles with respect to this axis, and thus is sensitive to the "lobe effect".

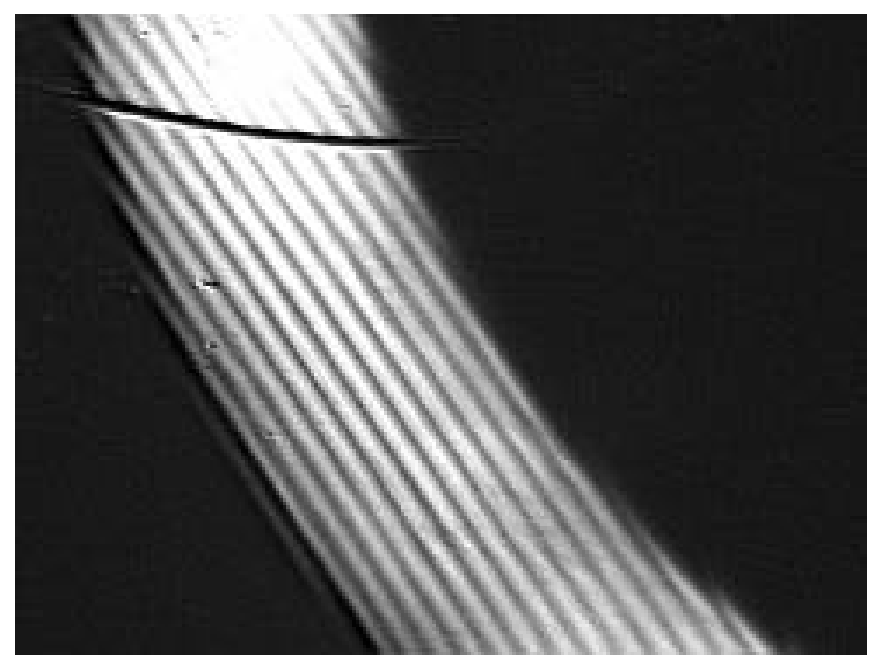

Figure 7. Image observed under a microscope using a "white" ring-type light. The periodic structure is evident. The dark line across the top is a $100 \mu \mathrm{m}$ wire placed on the top surface and used for scaling. The periodic structure was observed only at an specific angle, and only for the synthetic fused silica Suprasil Standard. No obvious periodic pattern was observed with the "high OH" Spectrosil 2000 [6].

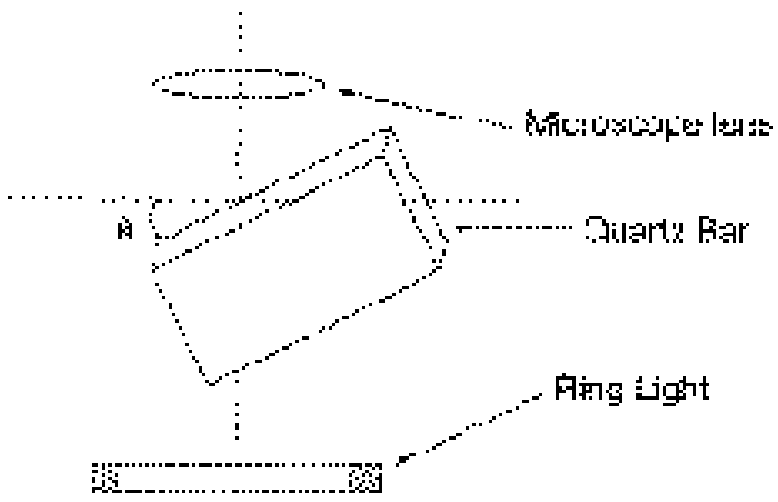

Figure 8. A microscope setup to observe the ring pattern as shown in Fig. 6 [6]. 

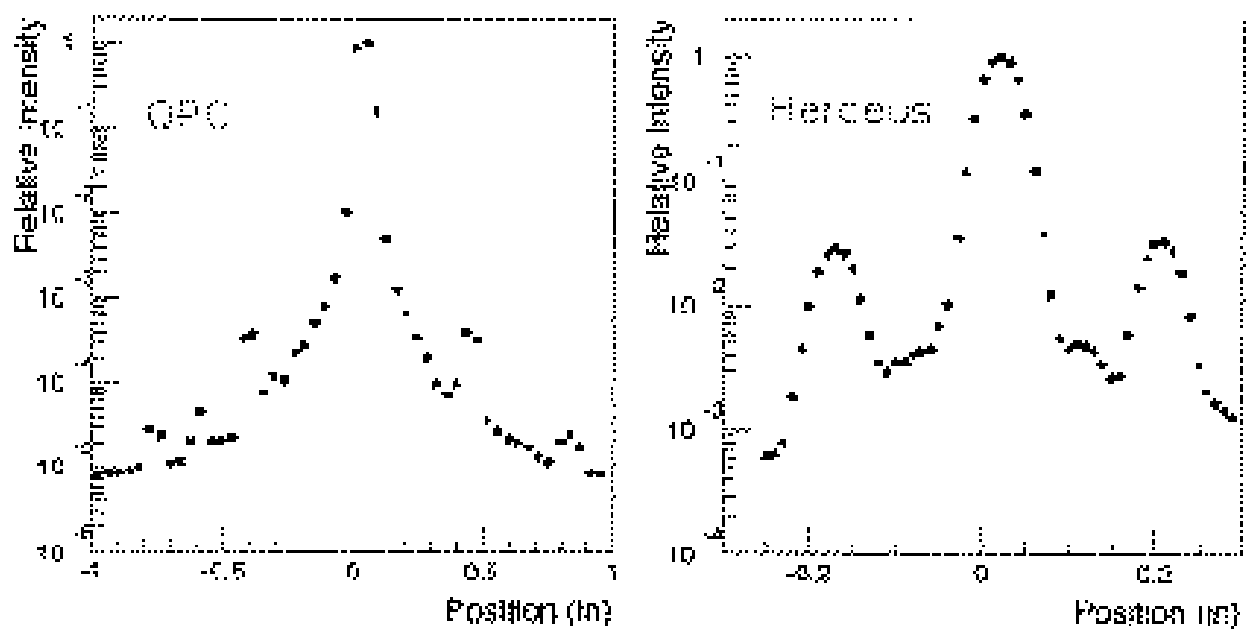

Figure 9 An interference pattern observed with a HeNe laser $(633 \mathrm{~nm})$ for QPC material (left) and Heraeus Spactrasil material (right). Note different scales [6].

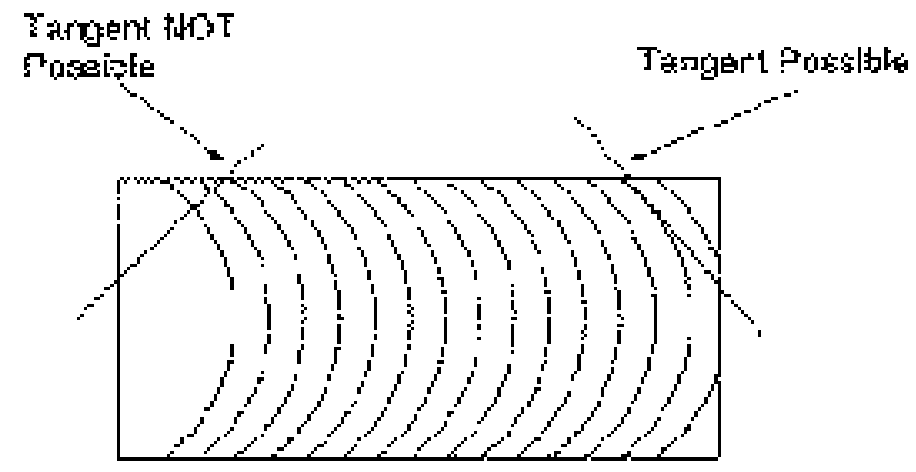

Figure 10. A possible explanation of origin of the interference is in the layering of the $\mathrm{SiO}_{2}$ material within the ingot.
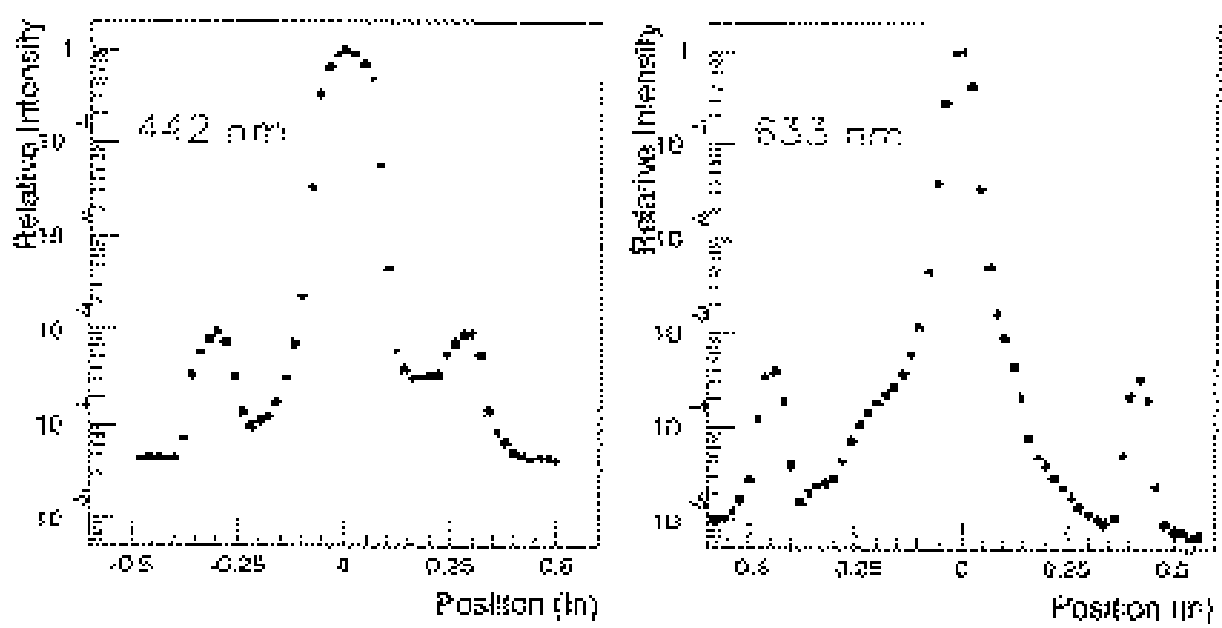

Figure 11. An interference pattern observed at two different wavelengths for the QPC material. The difference in the width of the peaks is due to the different spot size of the $\mathrm{HeNe}$ and $\mathrm{HeCd}$ laser beams [6]. 
A more challenging exercise is to explain the periodic pattern shown in Fig. 7, which was produced with a white ring light. A possible method to explain it is to assume that the periodic structure of the refraction index of the fused silica modulates the refraction angle of light rays as they enter the fused silica. In this model, we would not loose the light on average, there is just a periodic modulation of the light intensity. From the point of view of DIRC, we would not loose photons, we would affect their angular resolution. Although this explanation seems reasonable, it has not been directly proven experimentally.

Based on these tests, DIRC has chosen QPC Spectrosil 2000 as the material for bars.

\section{FUSED SILICA BAR TRANSMISSION AND INTERNAL REFLECTION COEFFICIENT}

Figure 12 shows a schematic of the setup that has been used to measure the bar transmission and relative internal reflection coefficient [10]. A He-Cd laser provides a vertically polarized laser beam with a wavelength of 442 or $325 \mathrm{~nm}$. The bar can be scanned through the laser beam using an actuator controlled by a Macintosh computer running LabView software program. The transmission was measured along the axis of the bar. The reflection coefficient was measured by allowing many bounces within the bar - see Fig. 13. The computercontrolled setup measured the relative internal reflection coefficient, which could be normalized by comparison with a reference bar whose absolute reflection coefficient was measured by the method described in the next chapter. The laser beam enters the bar at the Brewster angle (see Fig. 12), which simplifies the overall problem by allowing the measurement of only two intensities rather than four required in the absolute measurement. The advantage of the automatic method is that it scanned about 75 grid-points across a large surface area. A number of bars have been tested in this setup. The average relative internal reflection coefficient was $0.9996 \pm 0.0001$, the average transmission was $99.9 \pm 0.1 \% /$ meter at $442 \mathrm{~nm}$, and $98.9 \pm 0.2 \%$ at $325 \mathrm{~nm}$. Figure 14 shows an example of measurement results at $442 \mathrm{~nm}[11]$.

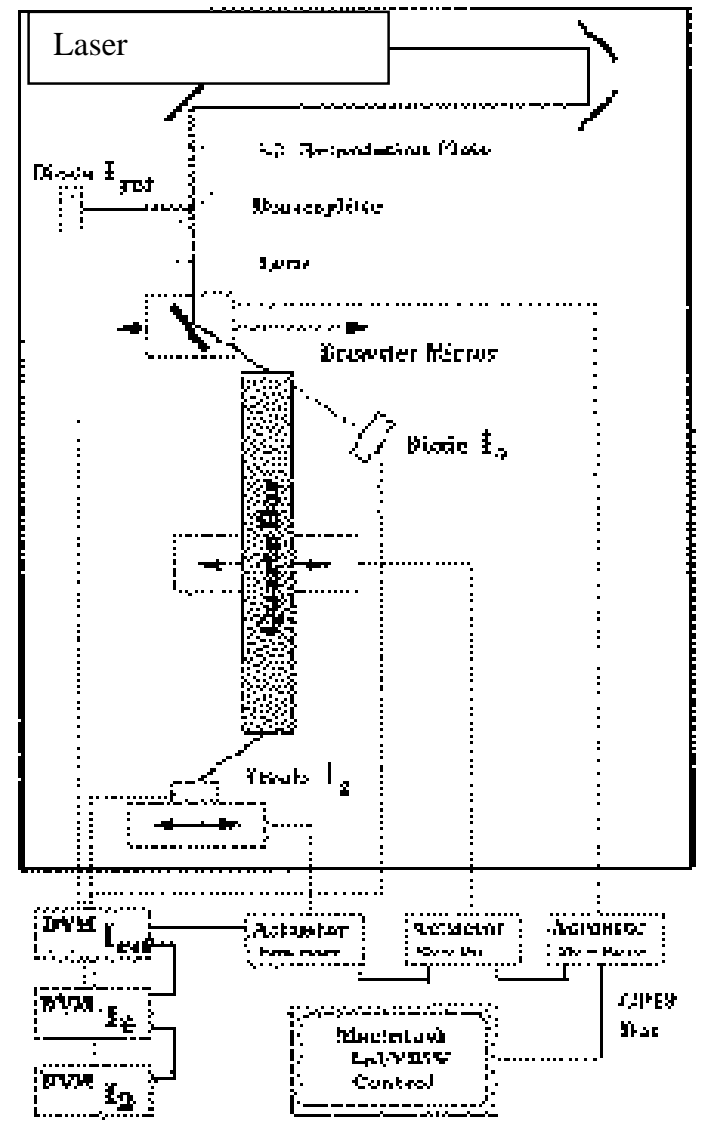

Figure 12. Computer controlled setup used to measure fused silica bar transmissions and the relative internal reflection coefficient [10]. 


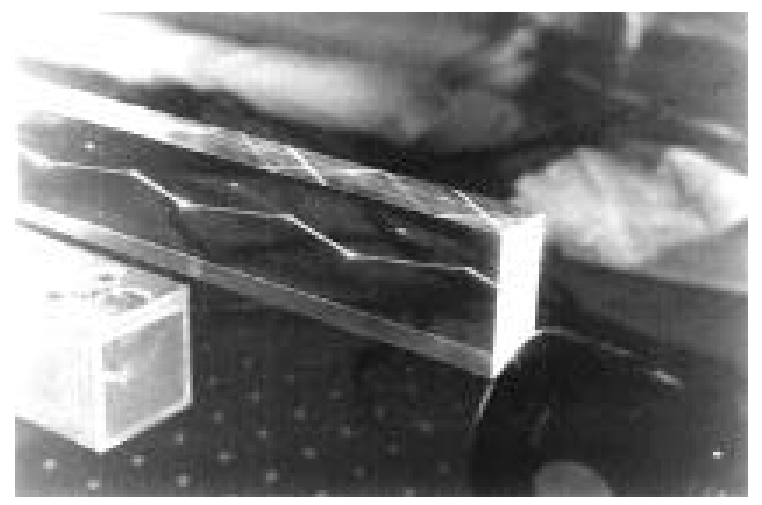

Figure 13. A laser beam bouncing in the fused silica bar during the relative internal reflection coefficient measurement [10].

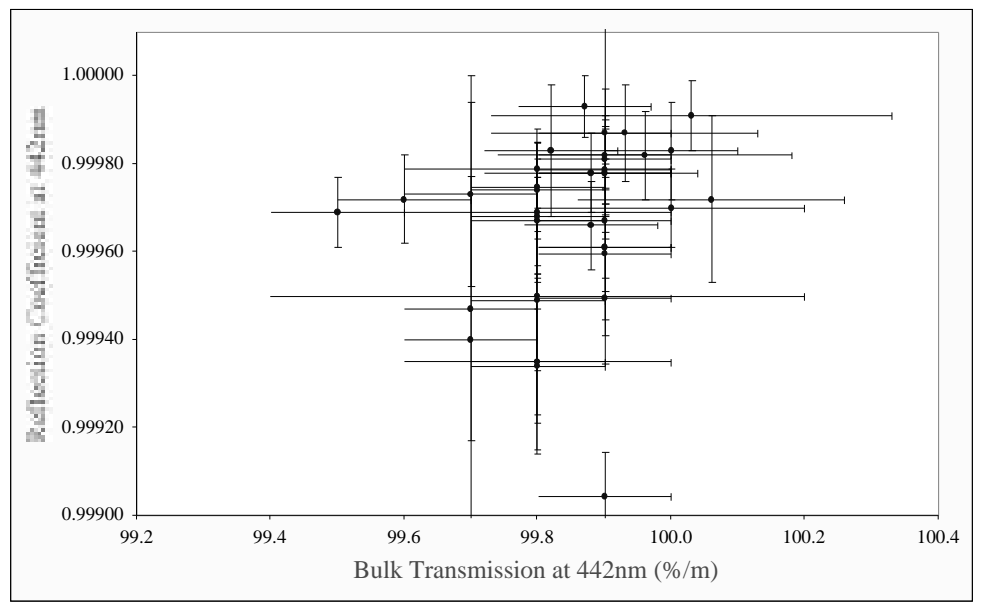

Figure 14. Measurements of transmission and relative internal reflection coefficient at a wavelength of 442nm [11].

\section{FUSED SILICA BAR INTERNAL REFLECTION COEFFICIENT AS A FUNCTION OF WAVELENGTH AND SURFACE POLLUTION}

The fused silica bar used in this measurement is $1.2247 \mathrm{~m}$ long, $3.495 \mathrm{~cm}$ wide and $1.646 \mathrm{~cm}$ thick. The internal reflection coefficient was measured on the wide surfaces of the bar [5]. Prior to this measurement, the bar surfaces were cleaned using an alumina powder technique. This is done by gently rubbing the fused silica surface with $0.3 \mu \mathrm{m}$ alumina powder, which is mixed with clean water in a 1:10 ratio, ensuring that the surface chemical pollution was minimized. Cleaning was essential for optimum results. A randomly picked bar, which was not subjected to either the "alumina powder" cleaning or the regular "acetone/alcohol" DIRC cleaning procedures, could have a reflection coefficient lower by $\sim 0.0005$. During the DIRC construction, we carefully monitored the bar cleanliness using the relative measurements of the reflection coefficient $[11,12]$ normalized to carefully selected reference bars.

To measure the wavelength dependency, we used five laser wavelengths: 266, 325, 442, 543, and 633nm, which were provided by four different lasers: Nanolase solid state YAG laser (266nm), Lyconix He-Cd 4210N (325 or $442 \mathrm{~nm})$, Uniphase 1135 green $(543 \mathrm{~nm})$, and Uniphase red $(633 \mathrm{~nm})$. The intensity of the lasers was different, influencing the relative accuracy for each measurement (for example, the Hamamatsu photodiode currents were $\sim 500-600 \mu \mathrm{A}$ at $442 \mathrm{~nm}, \sim 20-25 \mu \mathrm{A}$ at $325 \mathrm{~nm}, \sim 10-15 \mu \mathrm{A}$ at $266 \mathrm{~nm}, \sim 20-25 \mu \mathrm{A}$ at $543 \mathrm{~nm}$, and $\sim 500-$ $550 \mu \mathrm{A}$ at $633 \mathrm{~nm})$. Similarly, laser stability varied, with the $266 \mathrm{~nm}$ Nanolase being the least stable one. 


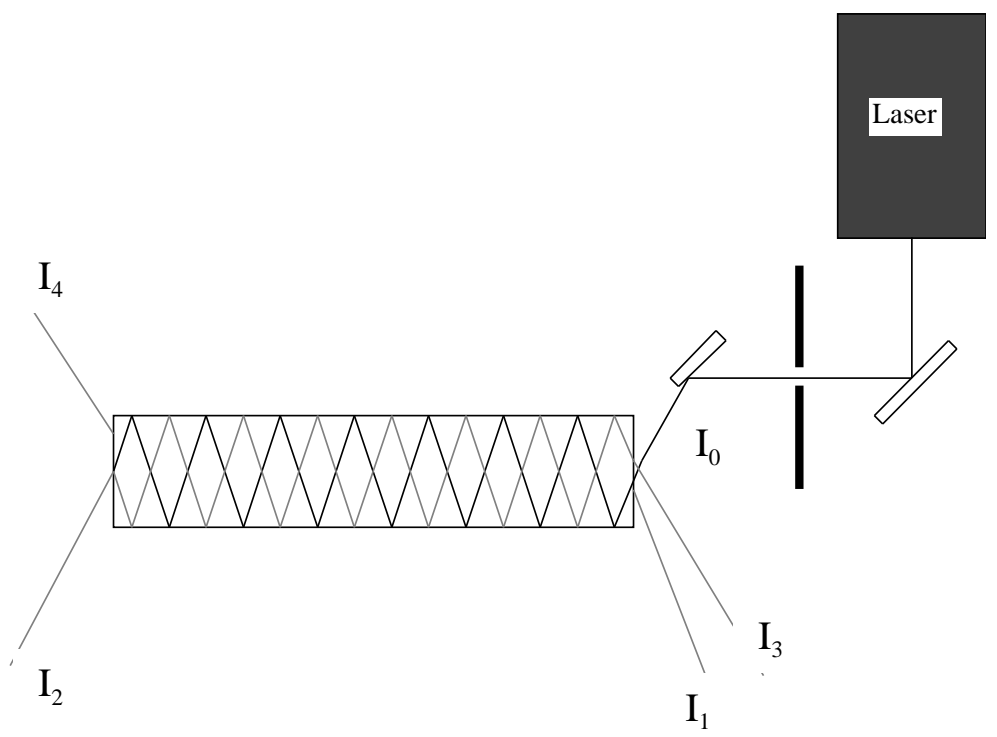

Figure 15. A schematic layout of the experiment to measure the reflection coefficient.

One could adopt a complicated method to measure the internal reflection coefficient, which assumes a complete optical analysis, including measurements of the entrance and exit angles. However, we have invented a simpler method, called the "calorimetric" method [13]. This method simply measures five light intensities (see Fig. 15), the number of light bounces, and also uses bar dimensions, i.e., no entrance or exit laser light angles are present in the measurement. The measurement was made by hand with a single photodiode measuring all intensities. The photodiode was equipped with a diffuser to improve its non-uniform response; however, it was still necessary to peak the diode by hand to achieve the reproducible results. We used the second photodiode to monitor the laser intensity. Both photodiodes were synchronized during the readout. The internal reflection coefficient $[r]$ is measured absolutely with this technique. The starting equation is:

$$
\left(\left(\left(I_{0}-I_{1}\right) r^{N}-I_{2}\right) r^{N}-I_{3}\right) r^{N}=I_{4}
$$

which in turn leads to

$$
\mathrm{I}_{0}=\mathrm{I}_{1}+\mathrm{I}_{2} \mathrm{x}+\mathrm{I}_{3} \mathrm{x}^{2}+\mathrm{I}_{4} \mathrm{x}^{3}
$$

The solution $\mathrm{X}$ is related to the coefficient of internal reflection $[\mathrm{r}]$ through the following equation:

$$
\begin{aligned}
& \mathrm{x}^{-1}=\mathrm{r}^{\mathrm{N}} * \exp \left\{-\frac{\mathrm{L}}{\Lambda} * \sqrt{\left[1+\left(\frac{\mathrm{bN}}{\mathrm{L}}\right)^{2}\right]}\right\} \\
& =(\text { Reflection_coeff. }) \text { Transmission_coeff, }
\end{aligned}
$$

where $\mathrm{N}$ is the number of bounces, $\mathrm{L}$ is the length of the fused silica bar, $\mathrm{b}$ is the width of the fused silica bar, $\Lambda$ is the fused silica attenuation length, and $\mathrm{I}_{\mathrm{i}}$ the laser intensities. The laser setup was arranged to have $\mathrm{N}=54$ bounces at $442 \mathrm{~nm}$. The fused silica attenuation length $\Lambda$ is not an easy quantity to measure at long wavelengths using such a short bar. We decided to use the attenuation length of $\Lambda=499.5 \pm 167 \mathrm{~m}$ at $442 \mathrm{~nm}$ as a reference, and then scale it to any other wavelength $\lambda$ according to $1 / \lambda^{4}$, assuming Rayleigh's law. For example, this dependence gives $\Lambda \sim 2100 \mathrm{~m}$ at $633 \mathrm{~nm}$, which would be impossible to measure with good accuracy using a $\sim 1.2$ $\mathrm{m}$ long bar. 
A further improvement in accuracy is found, by adding another term in equation (2), which can be calculated from the measured intensities by integrating the infinite sum of higher order contributions:

$$
\mathrm{I}_{0}=\mathrm{I}_{1}+\mathrm{I}_{2} \mathrm{x}+\mathrm{I}_{3} \mathrm{x}^{2}+\mathrm{I}_{4} \mathrm{x}^{3}+\mathrm{I}_{5}
$$

where the correction term reduces to:

$$
I_{5}=\frac{I_{3}^{3}}{I_{2}\left(I_{2}-I_{3}\right)}
$$

This correction increased the coefficient typically by $\sim 0.0003$.

Another small improvement in the accuracy was a correction for photodiode response due to the finite size of the laser beam. As the beam size for each intensity $I_{i}$ changes, the correction is different for each $I_{i}$ component. These corrections vary from $1.006\left(\mathrm{I}_{0}\right)$ to $1.03\left(\mathrm{I}_{4}\right)$.

The measurement of the reflection coefficient may be influenced by a loss of light intensity due to the interference effect described in the previous chapter. This effect could occur at some laser angle orientations relative to the bar axis. We made sure that the escaping laser beams do not have small lobes. In addition, one does not expect a large effect for this type of fused silica.

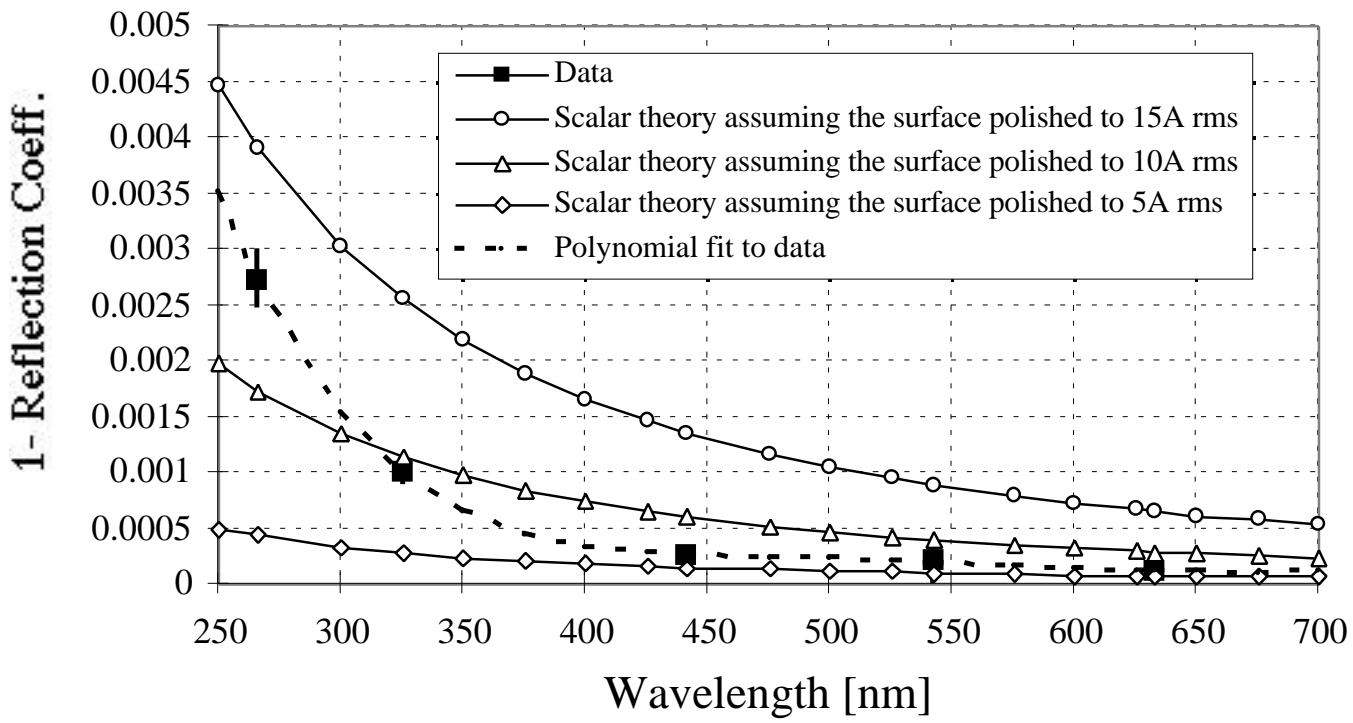

Figure 16. A comparison of the internal reflection coefficient measurements at five different laser wavelengths and the scalar scattering theory, assuming only random surface imperfections. Data are consistent with 5-8 A rms surface finish for wavelengths between 400 and $700 \mathrm{~nm}$. Below $\sim 350 \mathrm{~nm}$, the data does not agree with the simple scattering theory. The laser light bounced from the wide sides of the bar [5]. The graph shows also a polynomial fit to data.

Figure 16 shows the final data, plotted as (1-Reflection coefficient) $=\mathrm{f}$ (wavelength). The plotted errors are based on the rms of ten repetitive trials for each intensity component $\mathrm{I}_{\mathrm{i}}$. The systematic errors are harder to evaluate. They depend on many factors, such as surface quality variation, surface pollution (especially in the far UV region), method of the photodiode "peaking" (i.e., finding a spot yielding a consistent maximum reading), dust, background light in the room, lobe effect due to the refraction index variation, etc. To evaluate at least some systematic errors, the measurements were repeated many times, while varying the laser entrance point into the bar, the laser path within the bar, the number of bounces $\mathrm{N}$ (by a few), avoiding bright spots observed when hitting either chips or the bar supporting buttons, etc. After a lot of practice, one can assign a systematic error of about \pm 0.0003 to each measurement. Figure 16 also shows three curves based on the scalar reflection theory [14], assuming the fused silica surface finish of 5, 10, and $15 \AA$. The internal reflection coefficient is consistent with the surface finish between 5 and $8 \AA$ in the wavelength region between 450 and $650 \mathrm{~nm}$. However, it gets 
significantly smaller below 350nm, and its value is no longer consistent with the scalar theory. This discrepancy is not well understood, although a considerable amount of time has been spent checking the experimental results at 266 and $325 \mathrm{~nm}$. A possible explanation for the discrepancy in the UV region could be a chemical pollution, or near surface humidity. Figure 16 also shows a polynomial fit to data. This fit was used to evaluate the DIRC efficiency and mean wavelength response [5].

We also did extensive pollution tests to see if the internal reflection coefficient can be degraded by materials used for the construction of the bar boxes, gluing or during general handling procedures. The work, as well as a list of materials used in the tests, is presented in Ref. 15. The tests were performed for extended periods of time at room and elevated temperatures with and without added humidity. None of the materials, summarized in Table 2 , caused any significant decrease of the internal reflection coefficient at a level of about 0.0003 .

Table 2. Summary of the tests of pollution candidates [15].

\begin{tabular}{|c|c|c|c|c|}
\hline Pollution candidate & $\begin{array}{c}\text { Test duration } \\
\text { [days] }\end{array}$ & Temperature & Humidity & Relevance to DIRC \\
\hline Gluing station & 2 & room & dry & $\begin{array}{l}\text { Exposure to glue fumes during } \\
\text { bar gluing }\end{array}$ \\
\hline $\begin{array}{l}\text { DP-190 epoxy } \\
\text { (translucent) }\end{array}$ & 31 & room & dry & $\begin{array}{l}\text { Used as secondary glue to seal } \\
\text { bar boxes }\end{array}$ \\
\hline $\begin{array}{l}\text { DP-190 epoxy } \\
\text { (gray) }\end{array}$ & 31 & room & dry & $\begin{array}{l}\text { Used during construction of } \\
\text { bar boxes }\end{array}$ \\
\hline $\begin{array}{l}\text { Wet Hysol 1C-LV } \\
\text { epoxy }\end{array}$ & 42 & room & dry & $\begin{array}{l}\text { Used as primary glue to seal } \\
\text { bar boxes }\end{array}$ \\
\hline Wet SES-403 RTV & 54 & room & dry & Not used in DIRC \\
\hline Cured SES-403 RTV & 74 & room & dry & Not used in DIRC \\
\hline Packing foam for bars & 74 & room & dry & $\begin{array}{l}\text { Used to ship bars from Boeing } \\
\text { Co. to SLAC. }\end{array}$ \\
\hline EPDM gasket & 74 & room & dry & Used in gaskets for water seal \\
\hline $\begin{array}{l}\text { DIRC gas system } \\
\text { at BaBar }\end{array}$ & 90 & room & dry & $\begin{array}{l}\text { Final check of } \mathrm{BaBAr} \text { tubing } \\
\text { cleanliness }\end{array}$ \\
\hline $\begin{array}{l}\text { Wet Dow Corning } \\
3145 \text { RTV }\end{array}$ & 116 & room & dry & $\begin{array}{l}\text { Used during the construction } \\
\text { of the clean room }\end{array}$ \\
\hline Teflon sample & 116 & room & dry & Not used in DIRC \\
\hline Prototype bar box & 117 & room $/ 60^{\circ} \mathrm{C}$ & dry & $\begin{array}{l}\text { Initial test of bar box } \\
\text { cleanliness }\end{array}$ \\
\hline Epotek 301-2 epoxy & 1 & room & dry & $\begin{array}{l}\text { Used to glue bars, wedges and } \\
\text { windows }\end{array}$ \\
\hline Bar box buttons & 3 & room & dry & Used in bar box construction \\
\hline $\begin{array}{l}\text { Matheson pressure } \\
\text { regulator }\end{array}$ & 10 & room $/ 60^{\circ} \mathrm{C}$ & dry / wet & Used in BaBar gas system \\
\hline $\begin{array}{l}\text { Magnehelic pressure } \\
\text { gauge }\end{array}$ & 31 & room $/ 60^{\circ} \mathrm{C}$ & dry / wet & Used in BaBar gas system \\
\hline Disogrin O-rings & 75 & room $/ 60^{\circ} \mathrm{C}$ & dry / wet & Used in BaBar gas system \\
\hline
\end{tabular}

\section{RADIATION DAMAGE OF FUSED SILICA AND OPTICAL GLUES}

It is expected that the DIRC could get $0.5-1 \mathrm{krad} /$ year during its normal operation in 10 years. Of course, nobody can safely estimate a dose during the machine physics tuning, but it seems reasonable to insist that the the Cherenkov radiator is resistant up to at least 10-15 krad level.

For the initial DIRC prototype tests $[16,17]$ we used Vitrosil- $\mathrm{F}^{4}$, which is a natural fused silica material (from now on we call it "natural fused quartz"). Because of good results with it, based on optical performance, it was assumed that the BaBar DIRC would also use natural fused quartz. Radiation damage of the natural fused quartz was not expected in the early days of the DIRC proposal, at least at a dose level of 10-20 krads obtained

\footnotetext{
${ }^{4}$ Natural fused quartz material Vitrosil-F was made by Thermo-Syndicate Co.
} 
from photons with energy of few MeV. Therefore, it was rather surprising to find that the Vitrosil-F material lost $\sim 80 \%$ of transmission per meter at $325 \mathrm{~nm}$ after a radiation dose of only $\sim 7$ krads [13] (see Fig. 17). The DIRC physics prototype tests were done with this type of natural fused quartz. After the radiation damage problem was realized, we decided to test two other natural fused quartz materials, namely, JGS3-IR ${ }^{5}$ and T-08 ${ }^{6}$. We obtained equally bad results. In principle, one could partially recover the transmission using photo-bleaching ${ }^{7}$ (see Fig. 17), and/or a heat treatment ${ }^{8}$ at $442 \mathrm{~nm}$ and partially at $325 \mathrm{~nm}$. Such a "curing procedure" would be highly impractical to implement in BaBar. Therefore, it was decided not to use natural fused quartz, and instead, we switched to more expensive synthetic materials. To remind the reader, natural fused quartz is made out of crystalline quartz raw materials found in mines. Synthetic fused silica is made artificially out of a silicon tetrachloride, or other feedstock.

We have conducted two types of tests: (a) using short quartz samples $(\sim 10-20 \mathrm{~cm})$, where the transmission was measured typically with a monochromator, and (b) using long samples $(\sim 1 \mathrm{~m})$, where the transmission was measured with a He-Cd laser (LiCONix 200 series; model 4214NB).

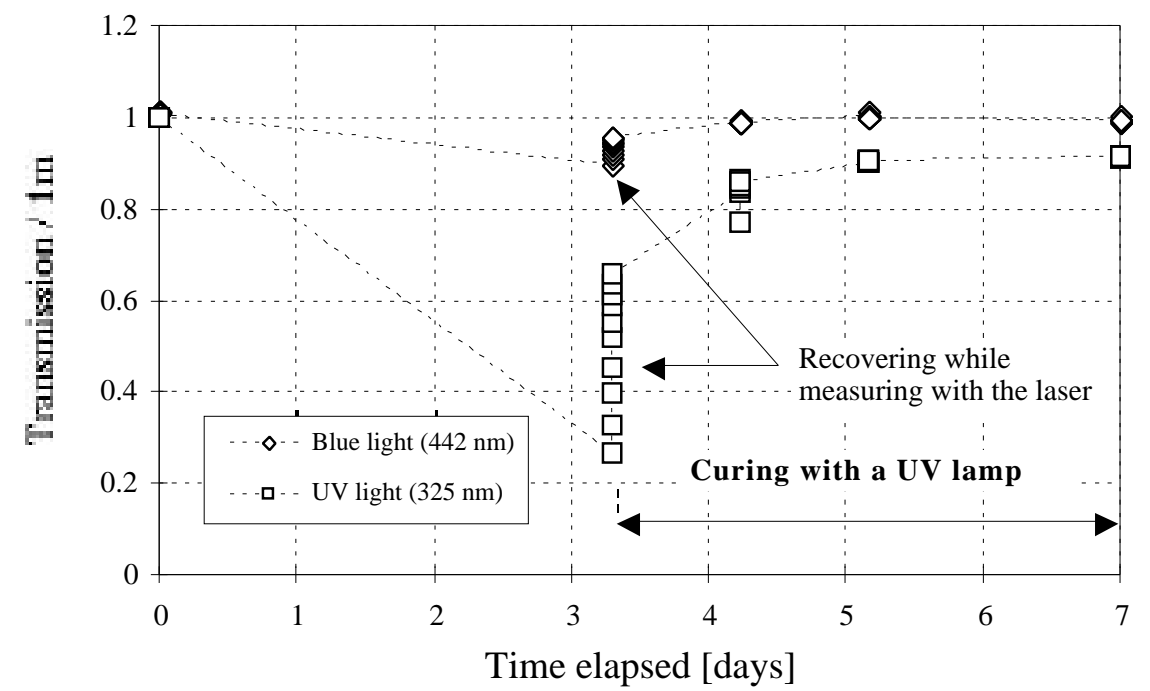

Figure 17. Radiation damage after radiation dose of $\sim 7 \mathrm{krads}$, of natural fused quartz Vitrosil-F, made by Thermo-Syndicate Co. The relative measurement (corrected for the reference bar) was done with a laser at 325 and $442 \mathrm{~nm}$ wavelengths. The sample length was only $\sim 30 \mathrm{~cm}$, and the result was extrapolated to $1 \mathrm{~m}$ length. The radiation damage was partially removed by a strong UV lamp. Furthermore, can also see a larger recovery for each laser measurement. The recovery induced by the laser affected only a region close the laser beam's spatial extent [13].

\subsection{Study of Radiation Damage of Short Samples of Synthetic Fused Silica}

We used the $\mathrm{Co}^{60}$ source facility available at SLAC to perform these tests [13,19]. Its present activity is about 14.1 Curie. A short sample can be placed very close to the source and one can achieve a dose up to 50-60 krads per day. The $\mathrm{Co}^{60}$ source gives two major photon emission lines, 1.173 and $1.333 \mathrm{MeV}$. There are some Compton electrons coming from the well concrete walls; we measured that they contribute about $10 \%$ to the total dose. The radiation dose was estimated using TLD dosimeters. The measurement was calibrated using (a) a theoretical estimate based on the geometry and known source activity corrected for its lifetime, (b) an ion chamber measurement, and (c) an opti-chromic dosimeter measurement. The measurements agreed to within $\sim 10 \%$.

\footnotetext{
5 Natural fused quartz material JGS3-IR was made by the Institute of Technology, Beijing 100081, P.R. China.

${ }^{6}$ Natural fused quartz material T-08 was made by Heraeus-Amersil Co.

${ }^{7}$ Photo bleaching is a recovery of lost transmission due to the radiation damage by a high intensity UV laser or lamp [18].

${ }^{8}$ A heat treatment can also recover the transmission loss due to the radiation damage.
} 


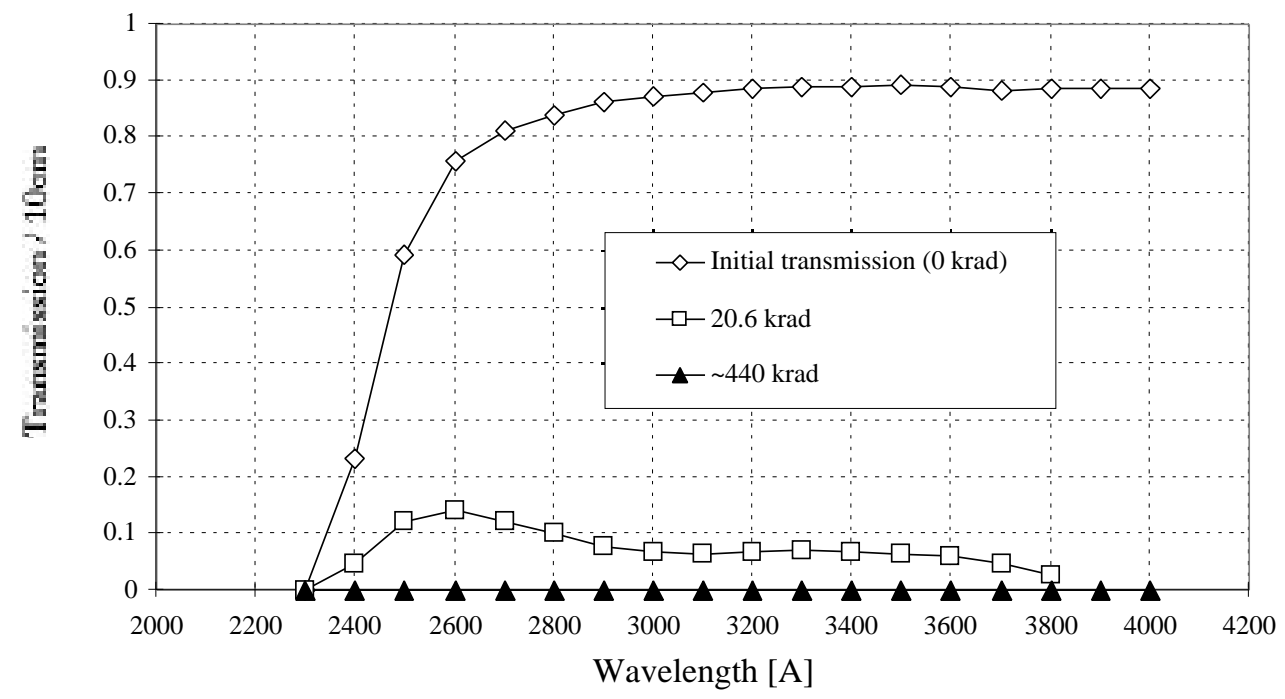

Figure 18. Radiation damage of natural fused quartz JGS3-IR sample. After a dose of $\sim 440 \mathrm{krads}$, the sample became almost black. Not corrected for the Fresnel reflection [13].

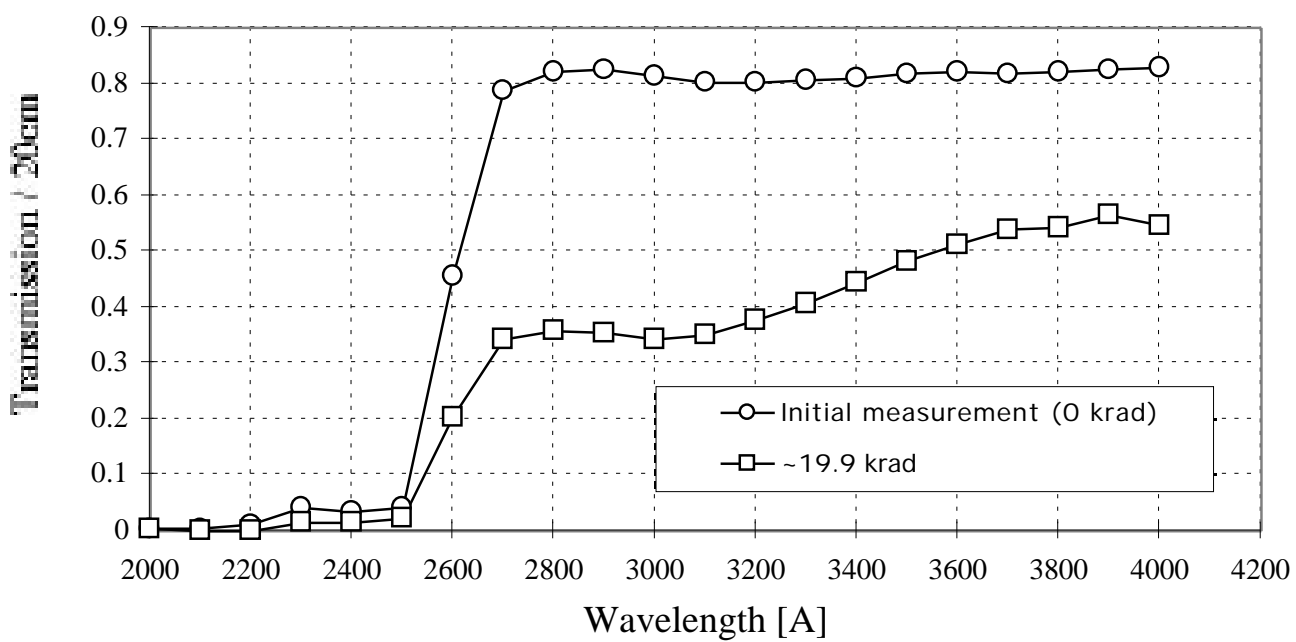

Figure 19. Radiation damage of natural fused quartz T-08 from Heraeus. Not corrected for the Fresnel reflection [13].

The transmission measurements of the short samples were typically done using the monochromator. These measurements have systematic errors at a level of 1\%. Figures 18 and 19 show examples of such measurements for the natural fused quartz samples. One can see a serious loss of transmission after a dose of only 20 krads. DIRC with the 5-meter long bars would not function at all given such transmission.

It was noticed that all three natural fused quartz samples differ from each other in their radiation response. Some differences were easily noticed during visual inspection. For example, the Vitrosil F samples remained perfectly clear to the naked eye even after $\sim 100 \mathrm{krad}$ (although its transmission was actually damaged, as discussed above). The JGS3-IR sample developed a uniform coffee-brown color after $\sim 20 \mathrm{krad}$, and became almost black after $\sim 440 \mathrm{krad}$. On the other hand, the T-08 sample was perfectly clear after $\sim 10 \mathrm{krad}$, and only slightly yellow after $\sim 334 \mathrm{krad}$, when inspected visually. However, we discovered that the monochromator PMT's single rates increased by a factor of $\sim 37$ after a dose of $\sim 10 \mathrm{krads}$, and by a factor of $\sim 8500$ after a dose of $\sim 334 \mathrm{krads}$ (the rate was approaching $\sim 450 \mathrm{kHz}$ ). We believe that the rate increase after the irradiation was caused by a very strong radio-luminescence [20] of natural fused quartz initiated by the $\mathrm{Co}^{60}$ radiation. Both Vitrosil-F and JGS3-IR samples did not show any noticeable radio-luminescence after the irradiation, at least at 
room temperature. The effect was not tested at elevated temperatures. We were not equipped to test very short radio-luminescence time constants. The first measurements were usually done within 30-60 minutes after the sample was removed from the radiation well.

It is clear that natural fused quartz is not a good candidate for the BaBar experiment, and therefore, we began to study the properties of synthetic fused silica material. We have tested four short synthetic fused silica samples, (a) JGS1-UV $92 \mathrm{~cm}$ x $2 \mathrm{~cm}$ x $10 \mathrm{~cm}$ sample, (b) Suprasil Standard $2 \mathrm{~cm}$ dia. x $20 \mathrm{~cm}$ long sample, (c) "high OH" Spectrosil 2000 ( 1000 ppm OH content) $2 \mathrm{~cm} \mathrm{x} 2 \mathrm{~cm}$ x $20.7 \mathrm{~cm}$ long sample, and (d) "high OH" Spectrosil B ${ }^{10} 2 \mathrm{~cm}$ dia. x $20 \mathrm{~cm}$ long sample. Figures $20-24$ show the results of this study.

Figure 20 shows transmission levels for several doses of the "high OH" Spectrosil B $20 \mathrm{~cm}$ long sample. We find that the material is radiation hard above $280 \mathrm{~nm}$. In the far UV region below $240 \mathrm{~nm}$, we observe some radiation sensitivity. However it is still within acceptable levels for the BaBar experiment. This sample showed a strong radio-luminescence after radiation exposure, as one can see in Fig. 21. The photonic activity was estimated with the monochromator's PMT, and was about 100 times more than normal after $\sim 12$ krads, and was decaying at a rate of about $10 \%$ after 2-3 minutes. The time interval between the end of the irradiation and the beginning of the transmission measurement was typically 30-40 minutes.

Figure 22 shows that JGS1-UV synthetic material is very radiation resistant. In fact, it is among best samples we have tested. This sample did not show any radio-luminescence after radiation exposure.

Figure 23 shows that the Suprasil Standard synthetic material showed the largest radiation damage for all synthetic materials we have tested so far. We find that the material is radiation hard for small doses up to 10-20 krads. However, when the dose was increased to $\sim 280 \mathrm{krads}$, we see a substantial transmission loss below $\sim 340 \mathrm{~nm}$. Furthermore, this particular material did show a strong radio-luminescence after radiation exposure.

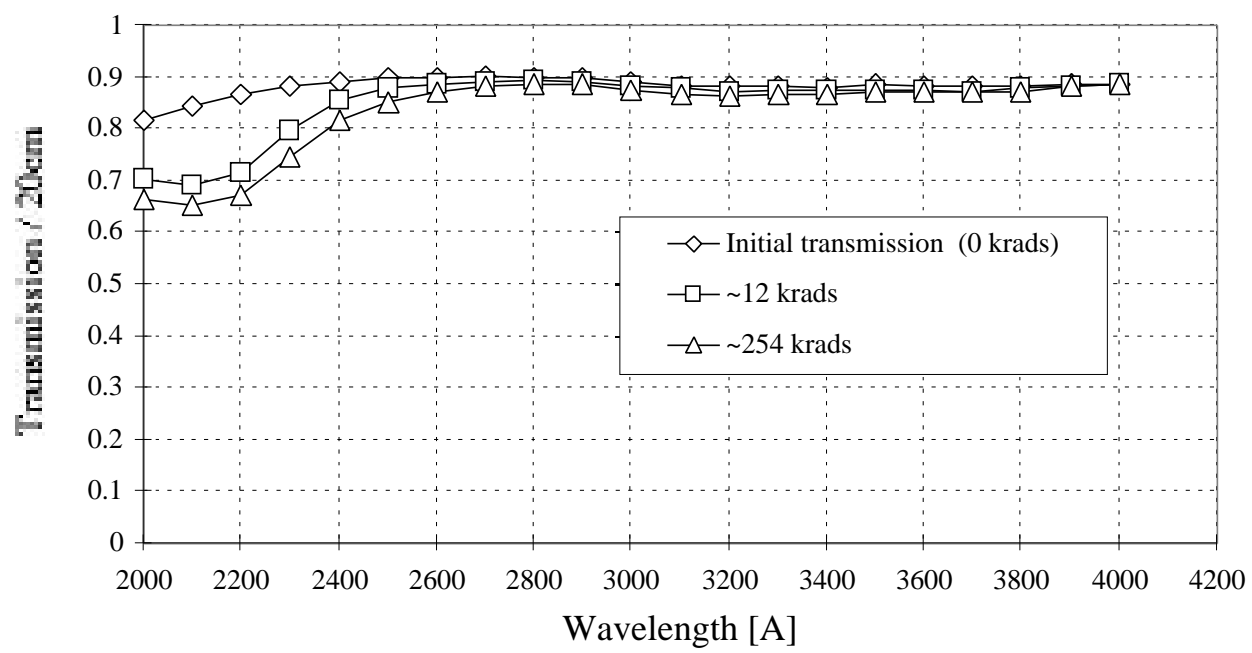

Figure 20. Radiation damage of the synthetic fused silica "high OH" Spectrosil B, made by QPC Co.. Not corrected for the Fresnel reflection [19].

\footnotetext{
${ }^{9}$ Synthetic fused silica material JGS1-UV was made by the Institute of Technology, Beijing 100081, P.R. China.

${ }^{10}$ Synthetic fused silica material Spectrosil B "high $\mathrm{OH}^{\prime}$ " was also made also by TSL and sold by QPC.
} 


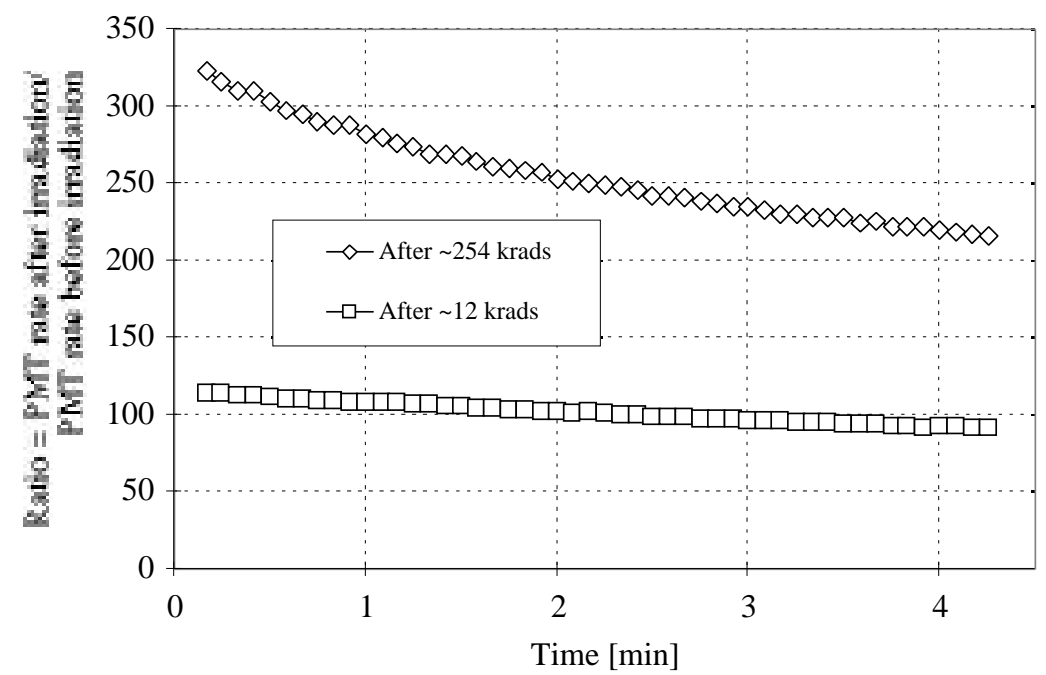

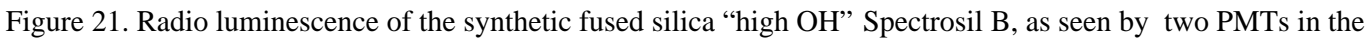
monochromator [19]. The measurement was done half an hour after removing the sample from the $\mathrm{Co}^{60}$ well.

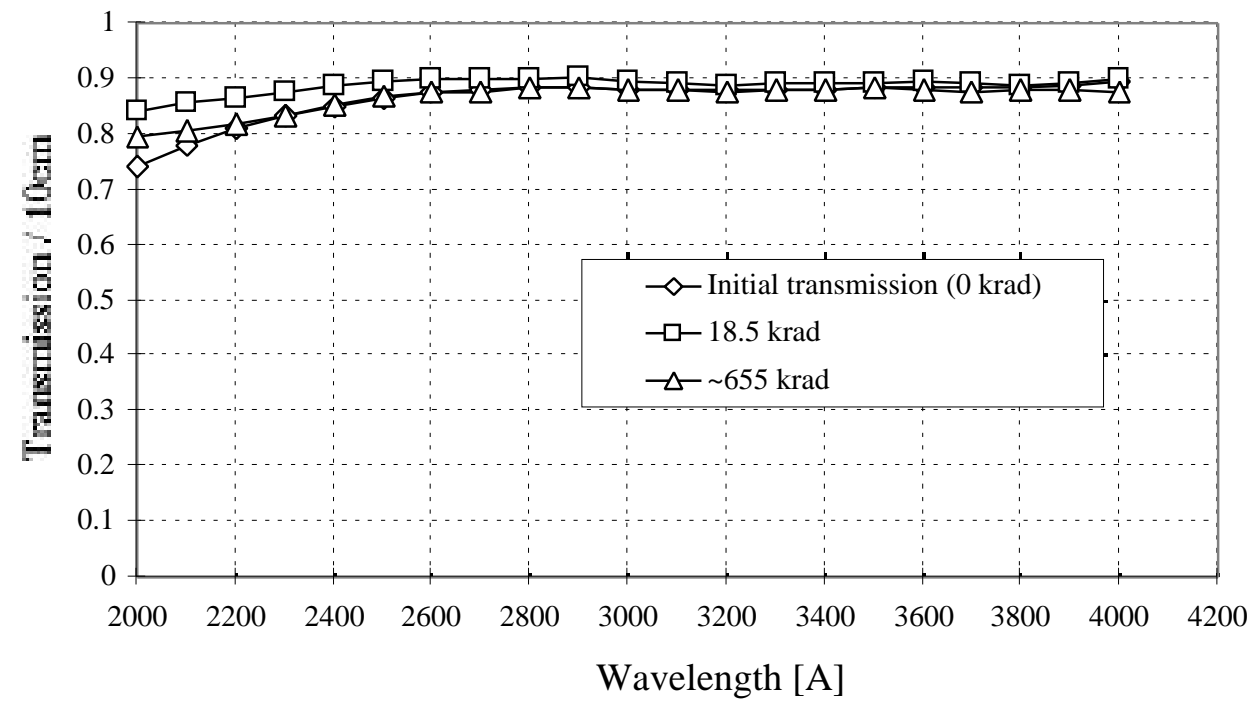

Figure 22. Radiation damage of the synthetic fused silica JGS1-UV sample. Not corrected for the Fresnel reflection [19].

Figure 24 shows transmission for several irradiation doses of the "high OH" Spectrosil $200020.7 \mathrm{~cm}$ long sample. This particular synthetic material shows a good radiation resistivity. We find that the material lost 2$3 \pm$ (1-2) \%/meter of transmission above $260 \mathrm{~nm}$ after a dose of $\sim 17$ krads. In the far UV region below $240 \mathrm{~nm}$, we observe larger losses. However, it continues to be well within the BaBar specs. This sample did not show any radio-luminescence after radiation exposure. Table 3 summarizes all radiation damage tests with all types of quartz.

The subject of radiation damage is complicated. The radiation damage is caused generally by quartz defects, such as oxygen vacancies, impurities ( $\mathrm{Ge}, \mathrm{Ti}, \mathrm{Al}$, alkali ions, $\mathrm{OH}$ ), etc. [20]. The defects can act as the color centers or become sources of radio-luminescence. The radio-luminescence is a well-known photon emission effect in quartz as well as in other materials. This technique has been used to date ancient pottery, because it always contained some quartz impurities (a sample of quartz is subjected to a temperature sweep and the 
resulting photon activity is measured with a PMT). One can identify the origins of different species of quartz. Not only can one identify a specific quartz defect from a given peak position in the radio-luminescent spectrum, but for the same quartz materials, such as the natural pink quartz, radio-luminescence begins at room temperature. Some materials have to be heated to more than $100^{\circ} \mathrm{C}$. Radio-luminescence occurs also in synthetic fused silica materials at some level.

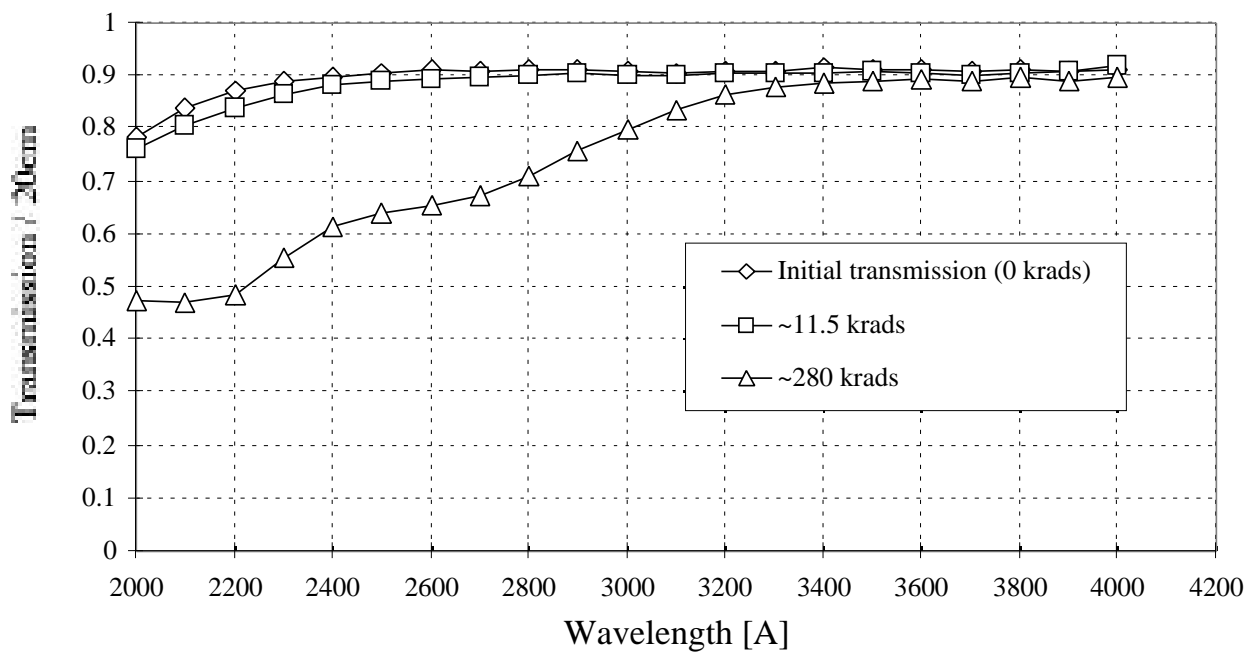

Figure 23. Radiation damage of the synthetic fused silica Suprasil Standard from Heraeus sample. Not corrected for the Fresnel reflection [19].

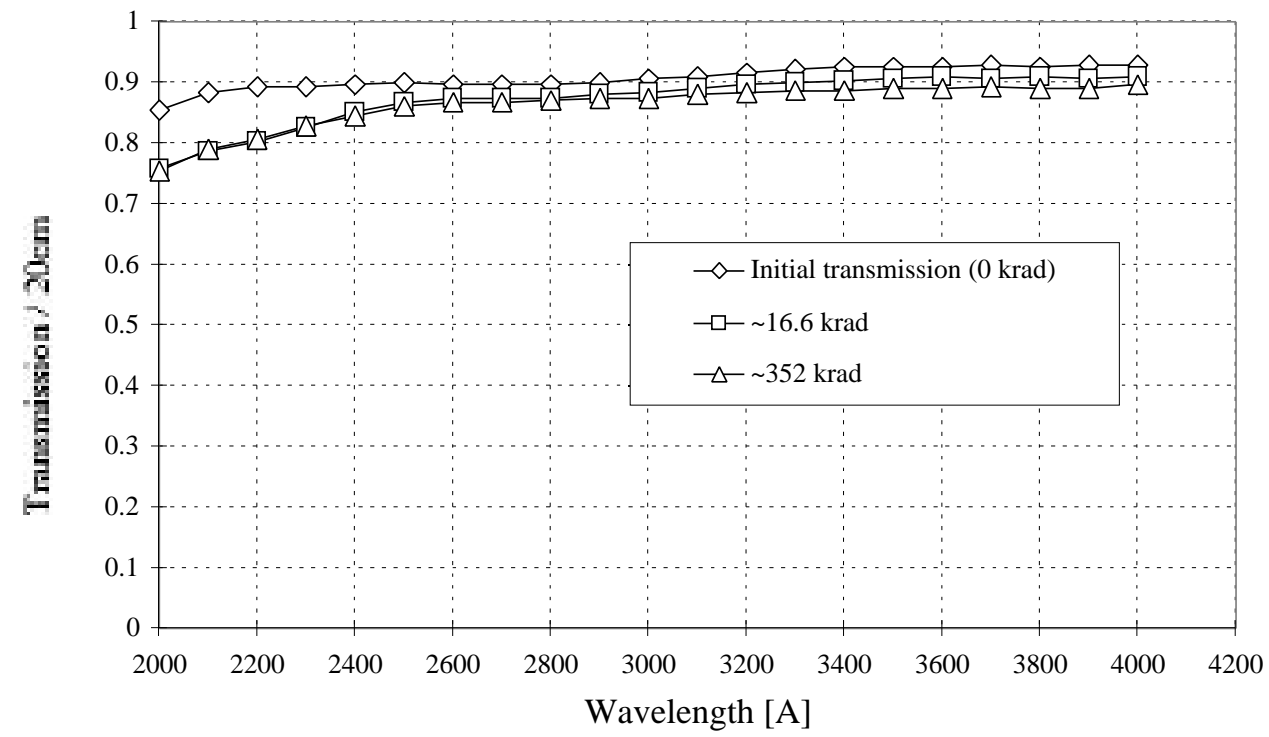

Figure 24. Radiation damage of the synthetic fused silica "high $\mathrm{OH}$ "Spectrosil 2000 sample. Not corrected for the Fresnel reflection [19]. 
Table 3. Radiation damage for various types of short natural and synthetic fused quartz samples $[13,19]$.

\begin{tabular}{|c|c|c|c|c|c|c|}
\hline $\begin{array}{l}\text { Quartz } \\
\text { material }\end{array}$ & Source & $\begin{array}{l}\text { Type of } \\
\text { quartz }\end{array}$ & $\begin{array}{l}\text { Special } \\
\text { comment }\end{array}$ & Visual change & $\begin{array}{l}\text { Radio } \\
\text { luminescence }\end{array}$ & $\begin{array}{l}\text { Transmission } \\
\text { loss }\end{array}$ \\
\hline Vitrosil F & TSL & Natural & $\begin{array}{l}\text { DIRC } \\
\text { prototypes }\end{array}$ & $\begin{array}{l}\text { No } \\
\text { (after } \sim 100 \mathrm{krad} \text { ) }\end{array}$ & $\begin{array}{l}\text { No } \\
\text { (after } \sim 100 \mathrm{krad} \text { ) }\end{array}$ & $\begin{array}{l}\text { Severe } \\
\text { (after } \sim 7 \mathrm{krad})\end{array}$ \\
\hline T-08 & $\begin{array}{l}\text { Heraeus } \\
\text { Amersil }\end{array}$ & Natural & & $\begin{array}{l}\text { Slight yellow } \\
\text { (after } \sim 330 \mathrm{krad} \text { ) }\end{array}$ & $\begin{array}{l}\text { Yes } \\
\text { (after } \sim 330 \mathrm{krad} \text { ) }\end{array}$ & $\begin{array}{l}\text { Severe } \\
\text { (after } \sim 10 \mathrm{krad})\end{array}$ \\
\hline JGS3-IR & $\begin{array}{l}\text { Beijing } \\
\text { Institute }\end{array}$ & Natural & & $\begin{array}{l}\text { Dark brown } \\
\text { (after } \sim 400 \mathrm{krad} \text { ) }\end{array}$ & $\begin{array}{l}\text { No } \\
\text { (after } \sim 400 \mathrm{krad} \text { ) }\end{array}$ & $\begin{array}{l}\text { Severe } \\
\text { (after } \sim 20 \mathrm{krad})\end{array}$ \\
\hline $\begin{array}{l}\text { Suprasil } \\
\text { Standard }\end{array}$ & $\begin{array}{l}\text { Heraeus } \\
\text { Amersil }\end{array}$ & Synthetic & & $\begin{array}{l}\text { No } \\
\text { (after } \sim 280 \mathrm{krad} \text { ) }\end{array}$ & $\begin{array}{l}\text { Yes } \\
\text { (after 280 krad) }\end{array}$ & $\begin{array}{l}\text { Small } \\
\text { (after } \sim 280 \mathrm{krad})\end{array}$ \\
\hline JGS1-UV & $\begin{array}{l}\text { Beijing } \\
\text { Institute }\end{array}$ & Synthetic & & $\begin{array}{l}\text { No } \\
\text { (after } \sim 650 \mathrm{krad} \text { ) }\end{array}$ & $\begin{array}{l}\text { No } \\
\text { (after } \sim 650 \mathrm{krad} \text { ) }\end{array}$ & $\begin{array}{l}\text { No } \\
\text { (after } \sim 650 \mathrm{krad} \text { ) }\end{array}$ \\
\hline $\begin{array}{l}\text { Spectrosil } \\
\text { 2000, "high } \\
\text { OH" }\end{array}$ & TSL & Synthetic & $\begin{array}{l}\text { Used in final } \\
\text { DIRC }\end{array}$ & $\begin{array}{l}\text { No } \\
\text { (after } \sim 180 \mathrm{krad} \text { ) }\end{array}$ & $\begin{array}{l}\text { No } \\
\text { (after } \sim 180 \mathrm{krad} \text { ) }\end{array}$ & $\begin{array}{l}\text { Small } \\
\text { (after } \sim 180 \mathrm{krad})\end{array}$ \\
\hline $\begin{array}{l}\text { Spectrosil B } \\
\text { "high OH" }\end{array}$ & TSL & Synthetic & & $\begin{array}{l}\text { No } \\
\text { (after } \sim 254 \mathrm{krad} \text { ) }\end{array}$ & $\begin{array}{l}\text { Yes } \\
\text { (after } \sim 254 \mathrm{krad} \text { ) }\end{array}$ & $\begin{array}{l}\text { Small } \\
\text { (after } \sim 254 \mathrm{krad} \text { ) }\end{array}$ \\
\hline
\end{tabular}

\subsection{Study of Radiation Damage of Long Synthetic Fused Silica Samples}

The transmission measurements of the long fused silica samples were done using the laser scanning system developed by the DIRC group [12] and described in chapter 3. This setup is capable of measuring the average transmission within a systematic error of about $0.2 \%$.

We have tested two synthetic fused silica materials: (a) a Suprasil Standard rod, $100 \mathrm{~cm}$ long and $26 \mathrm{~mm}$ in diameter, and (b) a "high OH" Spectrosil $2000 \mathrm{rod}, 137 \mathrm{~cm}$ long and $55 \mathrm{~mm}$ diameter [19].

The long fused silica samples are irradiated using a $\mathrm{Co}^{60}$ source at LBL. Its activity is $\sim 1400$ Curie. At a distance of 1 meter from the source, one can achieve a dose of $\sim 38 \mathrm{kR}$ per day. The bar is placed perpendicular to the geometric axis of the source. The radiation dose was measured with a Victoreen dosimeter measuring the exposure (in roentgen units [R], $1 \mathrm{R}=2.5810^{-4} \mathrm{Coul} \mathrm{kg}^{-1}$ ). The TLD dosimeter measures the absorbed dose (in rad units, $1 \mathrm{rad}=1.139 \mathrm{R}$ in tissue, it depends on the material and can change). In the following, the radiation doses will be given in terms of exposure dose, using roentgen $(\mathrm{R})$ units.

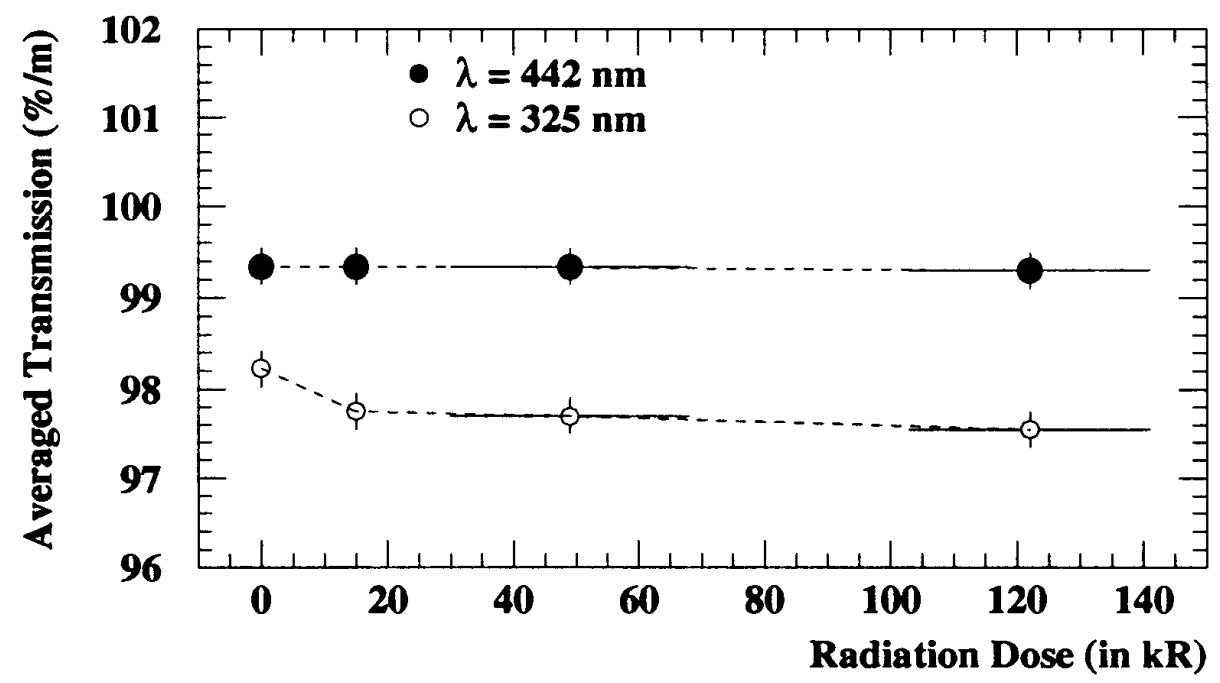

Figure 25. Radiation damage of the synthetic fused silica "high OH" Spectrosil 2000 (137 cm long) sample. This measurement was corrected for the Fresnel reflection at two surfaces. [19] 


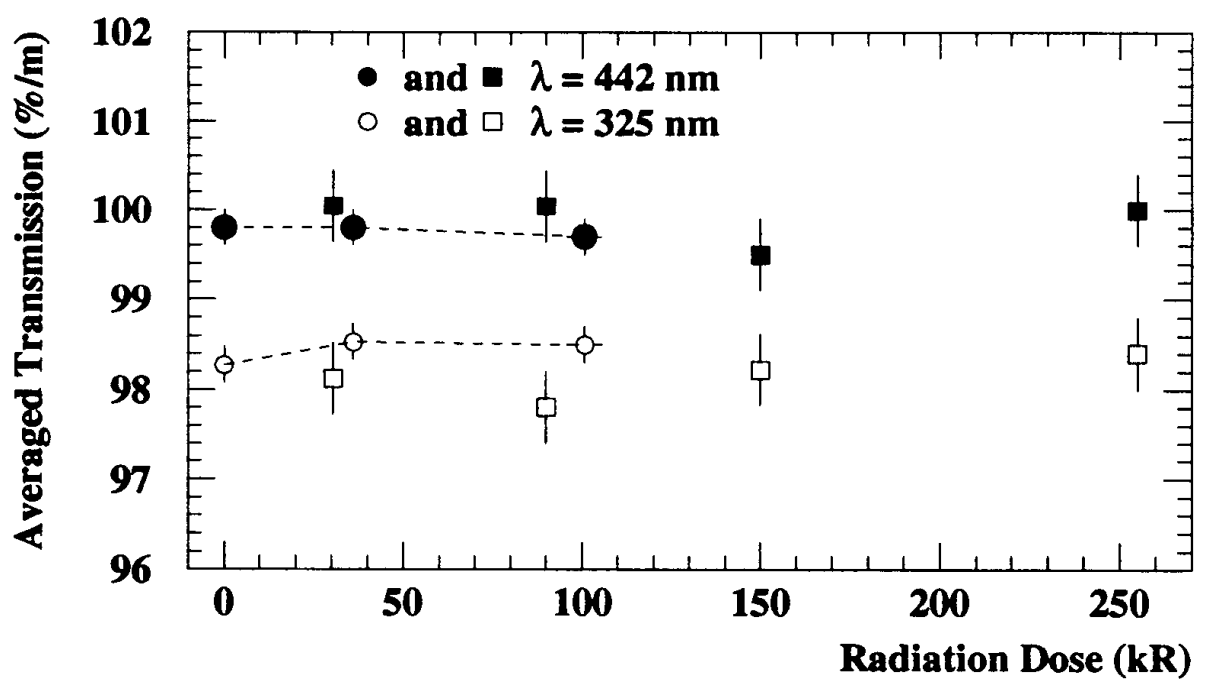

Figure 26. Radiation damage of the synthetic fused silica Suprasil Standard (100 cm long) sample. This measurement was corrected for the Fresnel reflection at two surfaces [19].

Figure 25 shows the transmission measurements for Spectrosil 2000. We find that the material lost $\sim 0.5 \%$ of transmission at $325 \mathrm{~nm}$ after $15 \mathrm{kR}$. Increasing the dose further did not result in additional transmission loss. No effect was observed at $442 \mathrm{~nm}$ for all radiation doses. Figure 26 shows the transmission measurements for Suprasil Standard. No significant transmission loss was observed at $325 \mathrm{~nm}$ or $442 \mathrm{~nm}$. This result is consistent with the radiation damage observed in the small samples, but does not extend into the UV.

Based on the radiation test results, we have found that the QPC Spectrosil 2000 fused silica material satisfies requirements for the radiation hardness needed to operate successfully for 10 years at BaBar.

\subsection{Study of Radiation Damage in Optical Glues}

It was also important to test the radiation hardness of the optical glues, which could fail either due to radiation or background induced photonic activity in the bar. We have tested five glue candidates: (a) EPOTEK 301-2 optical epoxy (it was the glue actually used for gluing of all DIRC fused silica bars), (b) SES-403 RTV, (c) SES-406 RTV, (d) KE-108 RTV, ${ }^{11}$ and (e) Rhodorsil-141 RTV. ${ }^{12}$ All optical glue samples were tested using the SLAC $\mathrm{Co}^{60}$ source facility. The following procedure was used: a glue sample was placed between two small fused silica windows, each $4 \mathrm{~mm}$ thick. This particular fused silica window was tested to be radiation resistant up to at least $70 \mathrm{krads}$, or more, but we did not test it further. It cuts the transparency at around $170 \mathrm{~nm}$, i.e., it does not influence the glue studies in this note. The glue samples were placed in the monochromator to check the initial transmission, then irradiated with a dose of about 60-70 krads, and then rechecked for transmission.

Figure 27 shows the overall transmission summary and the experimental setup used in measurements. Figure 28 shows the transmission for the EPOTEK 301-2 epoxy, which is an optical epoxy with a UV cut-off edge at $\sim 280 \mathrm{~nm}$. One can see a slight damage of the transmission at a $1 \%$ level, between 300 and $350 \mathrm{~nm}$, after a dose of $\sim 70$ krads. The thickness of the EPOTEK sample was $\sim 25 \mu \mathrm{m}$. This thickness is typically used for gluing bars together.

11 Optical RTV glues SES-403 RTV, SES-406 RTV, and KE-108 RTV are made by Shin-Etsu Co..

12 Optical RTV glue Rhodorsil-141 RTV was made by Rhone-Poulenc Co.. 


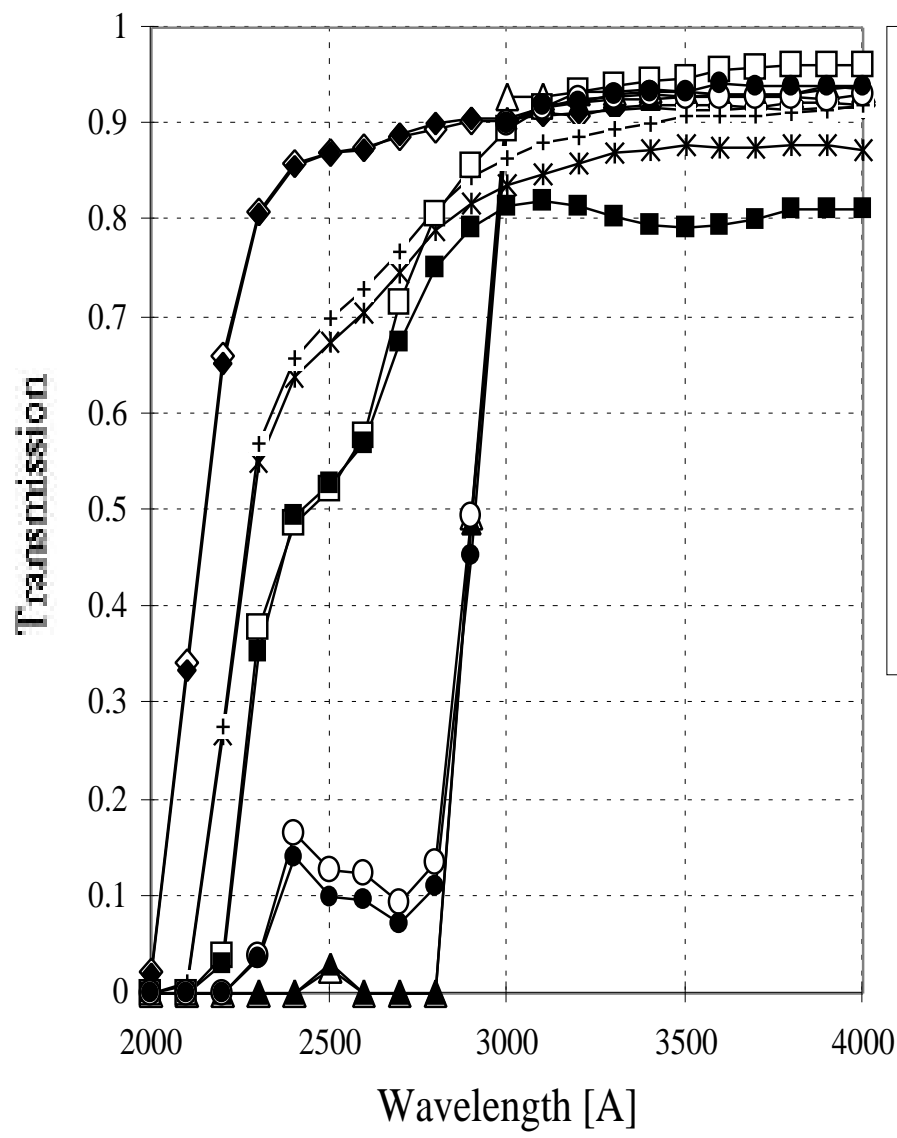

$\multimap$ SES-403 RTV, 0.035" thick, before irradiation

$\multimap$ SES-403 RTV, after $\sim 60 \mathrm{krads}$

$\checkmark$-EPOTEK 302-2, 0.001" thick, before irradiation

—-EPOTEK 301-2, after 70 krads

*-SES-406 RTV, 0.062" thick, before irradiation

-+-SES-406 RTV, after 50 krads

$\neg$-RHODORSIL-141 RTV, 0.058" thick, before

$\rightarrow$ RHODORSIL-141 RTV, after 70 krads

——-KE-108 RTV, 0.039" thick, before irradiation

$\multimap$ KE-108 RTV, after 132 krads

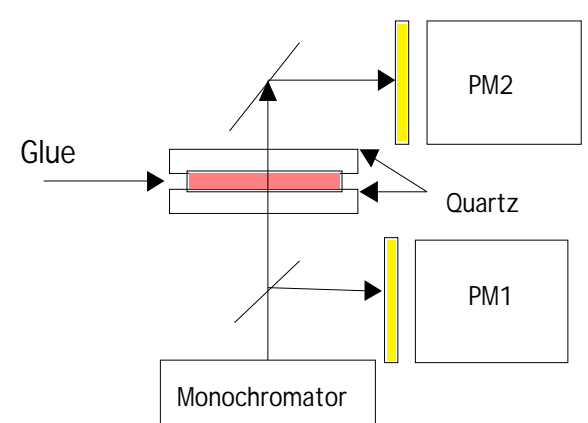

Figure 27. Radiation damage of various DIRC optical glue candidates with $\mathrm{Co}^{60}$ source.. The glue was placed between two fused silica plates, which were radiation hard. The glue sample was typically $\sim 25 \mu \mathrm{m}$ thick [19].

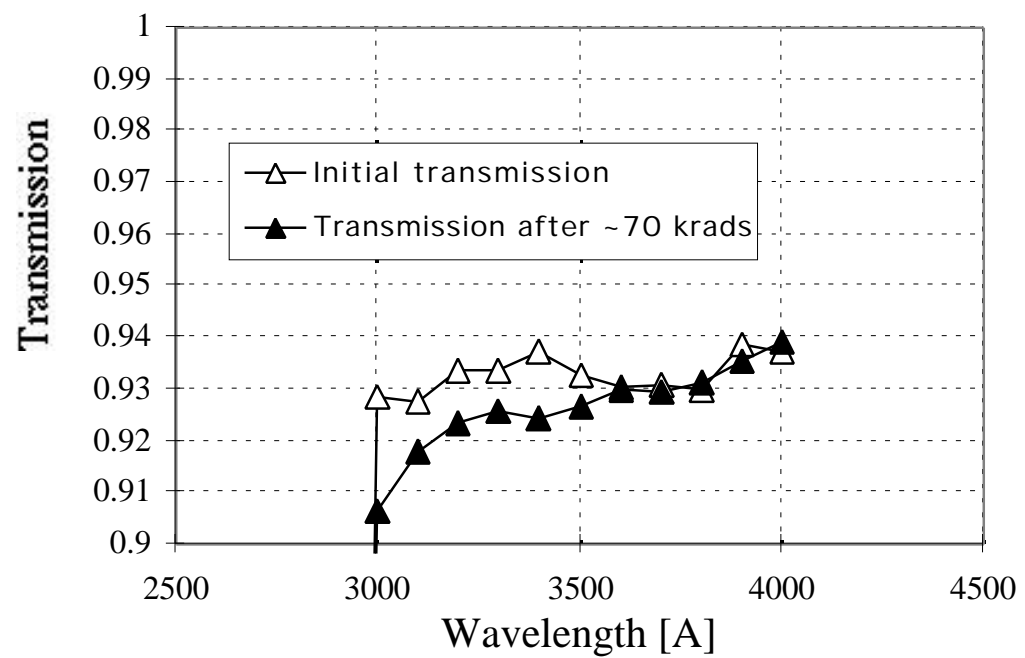

Figure 28. Radiation damage of the optical epoxy EPOTEK-301-2, which was used to glue together DIRC bars. The glue sample was $\sim 25 \mu \mathrm{m}$ thick, which is similar to a typical thickness for gluing bars together. This measurement was corrected for the Fresnel reflection at two surfaces [19]. 
Based on the radiation test results, we have found that the EPOTEK-301-2 epoxy, which was chosen to glue the bars together, also satisfies requirements for the radiation hardness needed to operate successfully for 10 years at BaBar. In addition, we have not observed any "yellowing" effects of this glue under a strong flux of photons.

\section{REFLECTION FROM THE FUSED SILICA BAR SUPPORTING SHIMS AND MIRRORS}

The mirror ${ }^{13}$ at the end of each bar is an important part of the DIRC enabling the capture of the Cherenkov light going forward into BaBar (the DIRC PMT readout is on the back side of the detector). Figure 29 shows the DIRC mirror reflectivity as a function of wavelength. The manufacturer's data was found to be consistent with our data at three different laser wavelengths 266, 325, and $442 \mathrm{~nm}$.

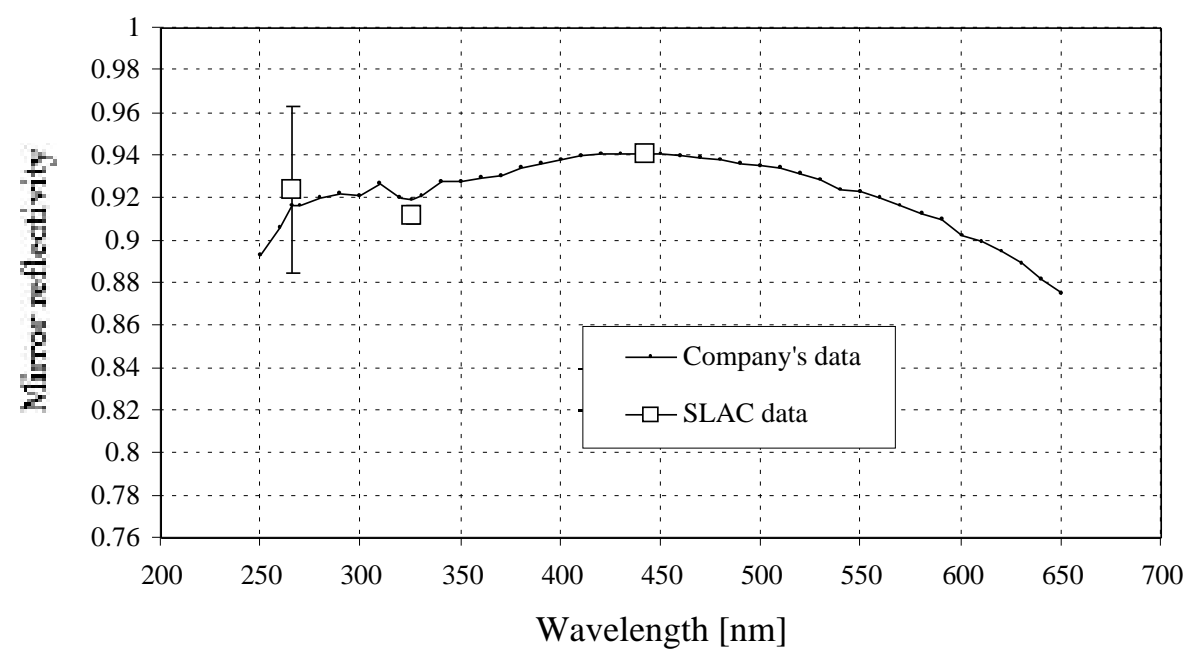

Figure 29. DIRC mirror reflectivity as a function of wavelength is shown. The data is measured with a laser, the mirror is in air, the laser beam is perpendicular to the mirror, and it is polarized vertically. The mirror manufacturer's data are measured with the monochromator [11].

The fused silica bars have to be supported within the bar box. The idea is to choose a material that minimizes the reflection loss when a photon reflects from it. At the same time, the coupling between the fused silica bars and the aluminum bar box must prevent scratching of the fused silica surface given the differential thermal expansion. Figure 30 indicates that, for example Nylon creates very large reflection losses. This is true for all of the soft plastic materials tested such as Teflon or Rubber. The harder plastic materials, such as Kapton or Mylar, perform better. Metals, such as Aluminum, perform even better. Figure 30 indicates that the reflectivity of any material depends on the pressure with which the material is pressed against the fused silica bar. To quantify this better, we constructed a shim press, which was calibrated to express the force per area in psi units. Figure 31 shows the reflection losses with Aluminum shim foils as a function of the load. One can see that the loss is less than $1 \%$ for typical practical loads. For comparison, Fig. 32 shows that the uncoated Kapton or Mylar shims would be a worse choice.

There is an interesting physical explanation of these tests: a portion of the internally reflecting wave extends beyond the fused silica boundary and probes the medium on other side. The reflection can occur with a certain probability as a result. This effect gets larger as the laser wavelength decrease and is also sensitive to the proximity to the critical angle. This effect is used for commercial pollution studies, usually in the infrared wavelength region. In our case, as the force on the shim gets larger, this effect increases, resulting in the reflection coefficient decrease.

Based on these tests, DIRC has chosen Aluminum as the material for shims between the bars, and Nylon for the supporting buttons separating the bars and aluminum bar box.

13 The DIRC mirrors were manufactured by United Lens Company, Inc., 259 Worcester Street, Southbridge, MA 01550-1325. 


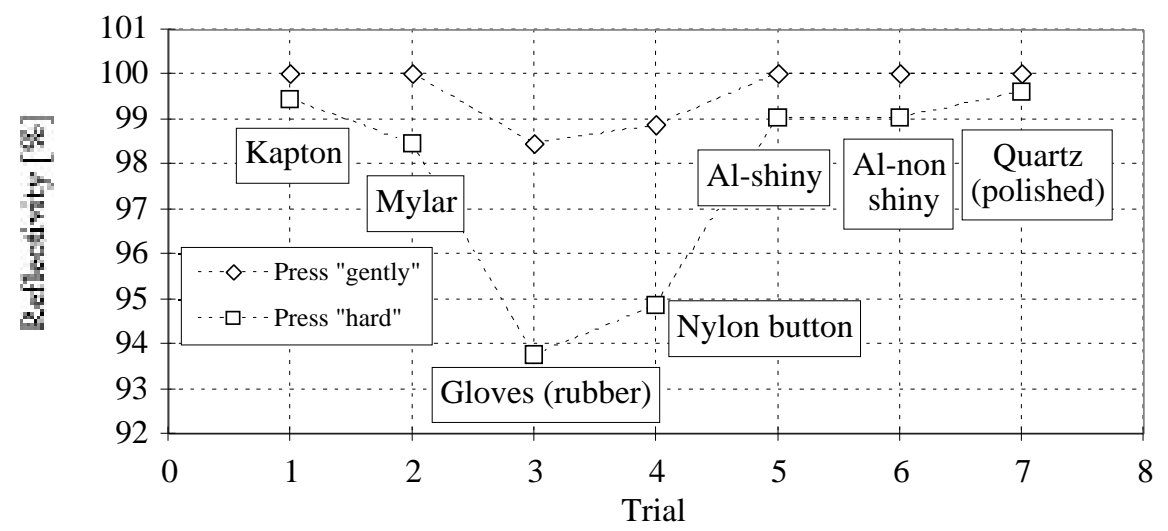

Figure 30. The single bounce reflectivity from various materials, which are attached to the bar at a place of reflection. This result motivated us to construct a press to quantify the results by knowing the loads on the shim [5].

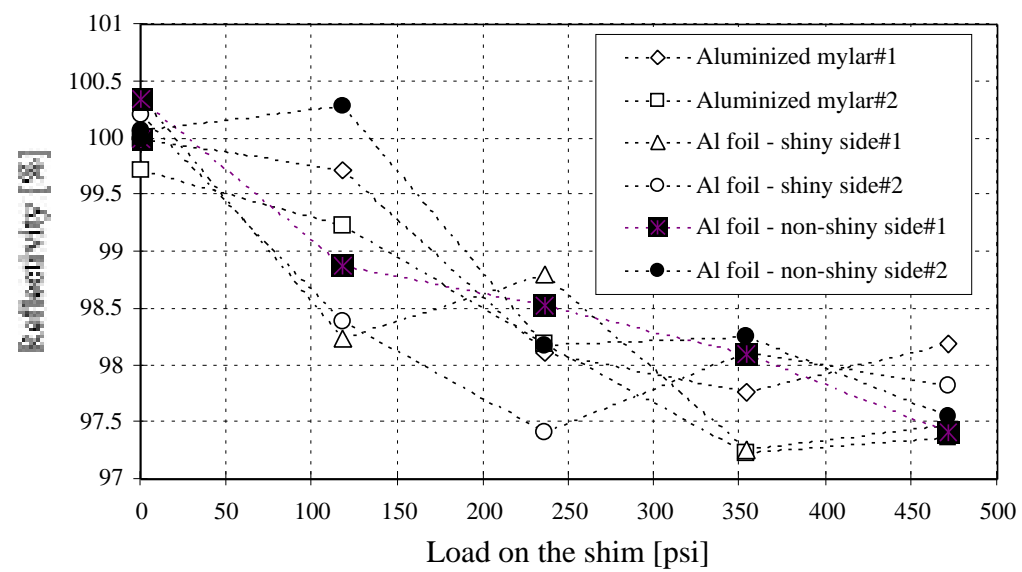

Figure 31. A single bounce reflectivity from the aluminum shims, which are attached to the bar at a point of reflection. We used the non-shiny aluminum shims to separate the bars in DIRC. The measurements were performed at 442 $\mathrm{nm}$ and incident angle of $21.5^{\circ}[5]$.

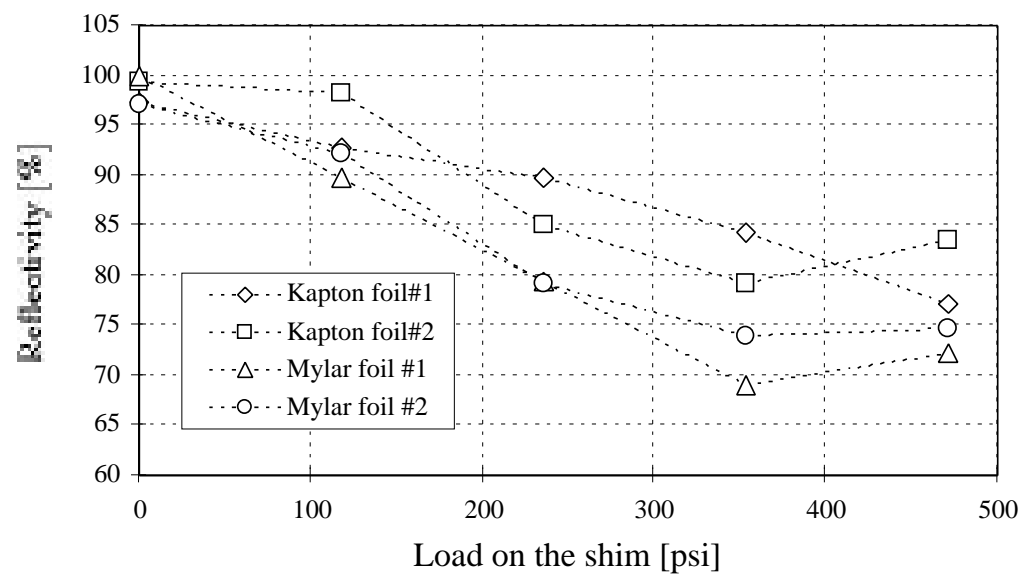

Figure 32. A single bounce reflectivity from uncoated Kapton or Mylar foils, which are attached to the bar at the point of reflection. The measurements were performed at $442 \mathrm{~nm}$ and incident angle of $21.5^{\circ}$ [5]. 


\section{DIRC FUSED SILICA BAR MECHANICAL QUALITY}

The mechanical bar properties, such as the bar surface orthogonality or damaged edges would clearly influence the quality of the Cherenkov angle image or the number of photons detected. The primary goal of our setup was to validate the manufacturer's ${ }^{14}$ bar measurements and provide independent measurements to doublecheck possible errors. To perform these QC checks at SLAC, we have built a digital microscope [8] and wrote several image-treating analysis programs based on the NIH Image software. ${ }^{15}$ One of our codes was based on a manual operation, where an operator would follow an edge of the bar visually, clicking on several points along the edge to digitize its coordinates. Such points were then used in the fit to find a straight line. Using two straight lines one could then define the orthogonality of two surfaces of the bar.

Another algorithmic approach was to use all available pixels within a given view, and this is what we will describe in more detail. Each digitized picture consists of an array of 640 by 480 pixels, each of which has 8 bits of grayscale information. For each picture, the bar edges are found by stepping through each row and column of the pixel matrix and looking for the transition between black and white with a simple threshold algorithm looking at the gray scale information. A typical bar edge would consist of several hundred points, which were used to define the edges. A special line-fitting algorithm was needed to reject those points lying on "chips". We have achieved fitted resolution of about 1 micron. This method was then used to measure the fused silica bar's angles by making an image including two edges. The manufacturer used a micrometer-based fixture to measure bar angles, and this method was occasionally calibrated with the auto collimator (this method yielded a precision of

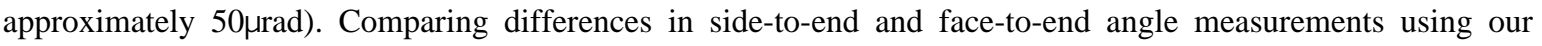
method and the Boeing method, yielded a fitted error of less than $0.15 \mathrm{mrad}$, which gave us a confidence that the two methods are consistent and can be used to reject bars that are out of tolerance. The face-to-side angle measurement comparison gave somewhat worse agreement of about 0.23 mrads. We have accepted bars to be used in the DIRC using the following statistical procedure: we use all four face-to-side angles on both sides of the bar and calculate the rms of the eight values. The production tolerance was $0.4 \mathrm{mrad}$ for the rms of eight values, with a goal of $0.25 \mathrm{mrad}$ in each angle. Figure 33 shows a good agreement between rms measurements by Boeing Co. and SLAC, which gave use a confidence in company's data.
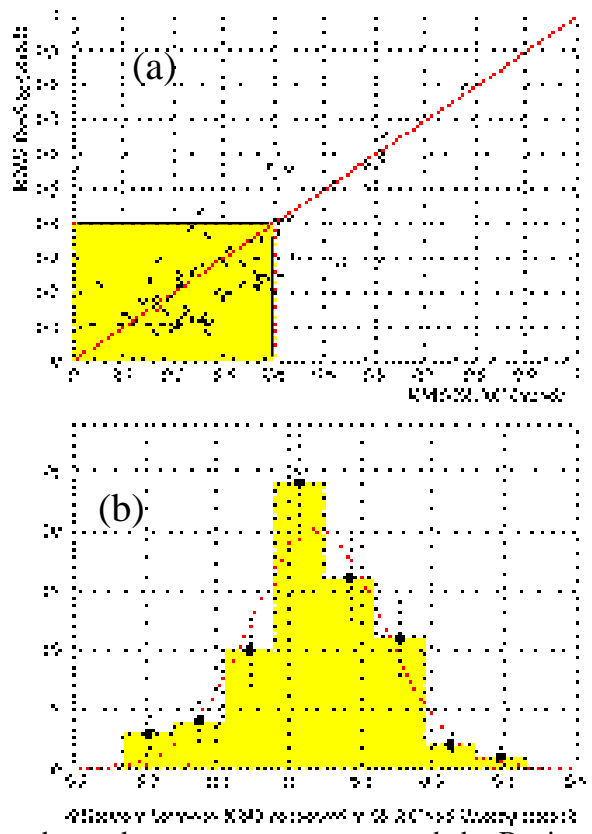

Figure 33. (a) Scatter plot shows the rms measurements made by Boeing and by SLAC. The rejected bars are outside of the shaded rectangle. (b) Difference between two measurements of the rms quantity defined in the text.

\footnotetext{
14 Boeing Optical Fabrication, 2511 C Broadbend Parkway NE, Albuquerque, New Mexico 87107.

$15 \mathrm{NIH}$ Image is a public domain image processing program.
} 
Finally, the digital treatment of the entire image allowed also the quantitative analysis of the "chippy" edges. Figure 34 shows an example of a good and bad bar edge as seen by the microscope and the corresponding software. The measured total integrated damage per bar was less than $3 \times 10^{-4}$ of the total area, of which the bar edges represented less than $20 \%$.
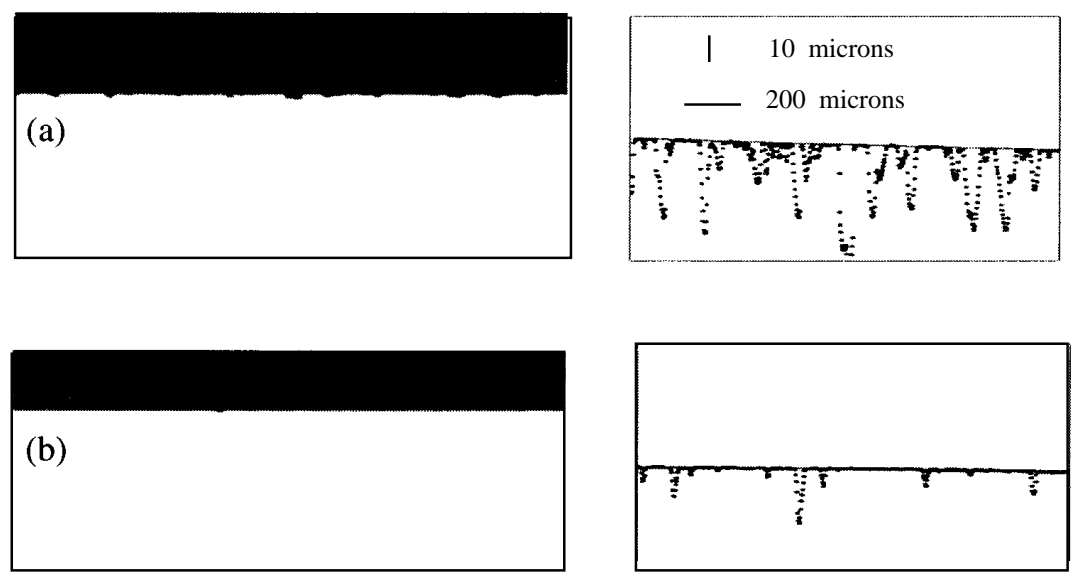

Figure 34. Example of (a) bad bar edge, as it appears on the Macintosh screen used for the microscope readout (left side), and the digitized version of the same edge by the off-line software analysis (right side), and (b) the same for the good bar edge, which was typical [8]. Note that even for badly damaged edges, the algorithm finds the "true" edge with good accuracy. The image has been greatly magnified in the y-direction.

\section{CONCLUSIONS}

1. This paper shows that natural fused quartz materials can suffer from serious radiation damage in the blue, and, particularly, in the UV regions after exposure to a radiation dose of 5-10 krad using a Co ${ }^{60}$ source. Although transmission recovery is possible using photo-bleaching and/or heating treatments, such "curing procedures" are not practical for BaBar. We also found that some natural fused quartz materials, most notably T-08, suffer from radio-luminescence at room temperature. All synthetic fused silica samples were found to be sufficiently radiation hard for BaBar. There are some small variations in the radiation damage rate among various materials, probably related to different levels of impurities.

2. All optical glue candidates tested so far are radiation hard at a level of 5-10 krads, which is the dose expected at BaBar. At the $70 \mathrm{krads}$ level, there is a 1\% degradation in transmission for the EPOTEK 301-2 epoxy, which was selected for gluing the bars.

3. The tests show that some synthetic fused silica materials, made in the form of ingots, show periodic optical inhomogenieties. This was an extremely important discovery, because in some instances this effect would make the DIRC inoperable.

4. We also present measurements of the wavelength dependency of, (a) the absolute value of the internal reflection coefficient, (b) the bar transmission, and (c) the mirror and supporting shim reflectivities.

5. All results presented in this paper provide supporting evidence of the importance of the extensive R\&D conducted during DIRC development and construction. Furthermore, it is now apparent that without this program, the DIRC would have not worked well.

\section{ACKNOWLEDGMENTS}

We would like to thank H. Krueger for important contributions during his 1996 summer stay at SLAC. We also thank R. Reif, M. McCulloch, and M. Schneider for their excellent technical help.

\section{REFERNCES}

1. B. Ratcliff, SLAC-PUB-6047, January, 1993.

2. This parameterization of the fused silica refraction index comes from the Melles-Griot Company's catalog, 
which is taken from I. H. Malitson, Journal of the Optical Society of America, Vol. 55, No. 10, October 1965 , pp. 1205-1209. The quoted accuracy of index is $\pm 3 \times 10^{-5}$.

3. The refraction index data come from N.I. Koshkin, M.G. Shirkevich, Handbook of Elementary Physics, 1982.

4. The EPOTEK Company provided data of refraction index of EPOTEK 301-2 optical glue at $589.3 \mathrm{~nm}$ (a sodium D line) and few wavelengths in the range of 1000-5000nm.

5. J. Va'vra, "Quartz absolute internal reflection coefficient, water transmission, mirror reflectivity, mean wavelength response, mean refraction index, and their effect on the expected number of photoelectrons and $\mathrm{N}_{\mathrm{o}}$," BaBar DIRC Note \#129, April 12, 2000; see also Nucl. Instr. \& Meth., A453 (2000)262-278.

6. M. Convery, B. Ratcliff, J. Schwiening and J. Va'vra, "Measurement of Periodic Structure in Synthetic Quartz,” BaBar DIRC Note \#130, April, 2000.

7. K. Abe et al., Nucl. Instr. \& Meth., A343 (1994) 74-86.

8. J. Cohen-Tanugi, M. Convery, M. McCulloch, R. Reif, J. Schwiening and J. Va'vra, "Development of a Digital Microscope for the DIRC Quartz bar Quality Control," BaBar DIRC Note \#132, May, 2000.

9. S. Yellin, "Diffraction from an Oscillating Refractive index," BaBar DIRC Note \#75, 1999.

10. H. Krueger, R. Reif, X. Sarazin, J. Schwiening and J. Va'vra, "The Optical Scanning System for the Quartz Bar Quality Control,” BaBar DIRC Note \#54, October 11, 1996.

11.J. Cohen-Tanugi, M. Convery, J. Schwiening and J. Va'vra, “The First DIRC Bar Box,” BaBar DIRC Note \#122, April 19, 1999.

12.H. Krueger, R. Reif, X. Sarazin, J. Schwiening and J. Va'vra, "Measuring the Optical Quality of Quartz Bars and the Coupling of RTV to the Window," BaBar DIRC Note \#40, May 20, 1996.

13.H. Krueger, M. Schneider, R. Reif and J. Va'vra, Initial Measurements of Quartz Transmission, Internal Reflection Coefficient and the Radiation Damage," BaBar DIRC Note \#18, January 5, 1996.

14.J. M. Elson, H. E. Bennett, and J. M. Bennett, Scattering from Optical Surfaces, Applied Optics and Optical Engineering, Vol. VII, Chapter 7, Academic Press, Inc., ISBN 0-12-408607-1979.

15. J. Cohen-Tanugi, M. Convery, J. Schwiening and J. Va'vra, "Study of the Internal Reflection Coefficient of DIRC bars as a Function of Quartz Surface Pollution”, BaBar DIRC Note \#131, April, 2000.

16. I. Adam et al., SLAC-PUB-7706, November, 1997.

17. R. Aleksan et al., Nucl. Instr. \& Meth., A397 (1997) 261.

18. C.E. Barnes, IEEE Trans. Nucl.Sci., Vol. Ns-29, No.6, Dec. 1982, p. 1479.

19.X. Sarazin, M. Schneider, Schwiening, R. Reif and J. Va'vra, "Radiation Damage of Synthetic Quartz and Optical Glues,” BaBar DIRC Note \#39, October 15, 1996.

20. S.W.S. McKeever, "Thermo-luminescence of solids," Cambridge Solid State Science Series, Cambridge University press, p. 187, 1988 edition. 